\title{
MDM2 prevents spontaneous tubular epithelial cell death and acute kidney injury
}

\author{
Dana Thomasova, ${ }^{*, 1}$ Martrez Ebrahim ${ }^{1}$, Kristina Fleckinger ${ }^{1}$, Moying Li ${ }^{1}$, Jakob Molnar ${ }^{1}$, Bastian Popper ${ }^{2}$, Helen Liapis ${ }^{3}$, \\ Ahmed M Kotb ${ }^{4,5}$, Florian Siegerist ${ }^{4}$, Nicole Endlich ${ }^{4}$ and Hans-Joachim Anders ${ }^{1}$
}

Murine double minute-2 (MDM2) is an E3-ubiquitin ligase and the main negative regulator of tumor suppressor gene p53. MDM2 has also a non-redundant function as a modulator of NF-kB signaling. As such it promotes proliferation and inflammation. MDM2 is highly expressed in the unchallenged tubular epithelial cells and we hypothesized that MDM2 is necessary for their survival and homeostasis. MDM2 knockdown by siRNA or by genetic depletion resulted in demise of tubular cells in vitro. This phenotype was completely rescued by concomitant knockdown of p53, thus suggesting p53 dependency. In vivo experiments in the zebrafish model demonstrated that the tubulus cells of the larvae undergo cell death after the knockdown of mdm2. Doxycycline-induced deletion of MDM2 in tubular cell-specific MDM2-knockout mice Pax8rtTa-cre; MDM2f/f caused acute kidney injury with increased plasma creatinine and blood urea nitrogen and sharp decline of glomerular filtration rate. Histological analysis showed massive swelling of renal tubular cells and later their loss and extensive tubular dilation, markedly in proximal tubules. Ultrastructural changes of tubular epithelial cells included swelling of the cytoplasm and mitochondria with the loss of cristae and their transformation in the vacuoles. The pathological phenotype of the tubular cell-specific MDM2-knockout mouse model was completely rescued by co-deletion of p53. Tubular epithelium compensates only partially for the cell loss caused by MDM2 depletion by proliferation of surviving tubular cells, with incomplete MDM2 deletion, but rather mesenchymal healing occurs. We conclude that MDM2 is a non-redundant survival factor for proximal tubular cells by protecting them from spontaneous $\mathrm{p} 53$ overexpression-related cell death.

Cell Death and Disease (2016) 7, e2482; doi:10.1038/cddis.2016.390; published online 24 November 2016

Renal tubular epithelial cells are continuously exposed to stress due to the hypoxia, hyperosmolarity and toxins exposure and it is rather remarkable that they can withstand those insults and still execute their physiological functions that is, water and solutes reabsorption and excretion. Acute exposures can lead to acute tubular necrosis underlying the clinical syndrome of acute kidney injury. In unchallenged kidneys, tubular epithelial cells divide at a very low rate. This minimal production of new cells supplies though enough tubular cells to balance the loss of the tubular epithelial cells into urine and guarantees the physiological turnover of tubule cells. Nevertheless, this turnover rate must be strictly controlled as even a small disproportion between cell death and cell proliferation would eventually result in nephron loss or significant increase in nephron size. ${ }^{1,2}$ In unstressed kidney remain the tubular cells in G0-G1, quiescent state. ${ }^{3}$ The mechanisms and factors necessary for the tubule cells homeostasis are not fully understood.

E3-ubiquitin ligase murine double minute-2 (MDM2) is the master negative regulator of tumor suppressor gene p53 and a non-redundant modulator of NF-kB signaling. ${ }^{4,5}$ As such MDM2 amplification or overexpression drives tumor growth and MDM2 blockade suppresses cancer development. ${ }^{6,7}$ In acute kidney injury caused by primary glomerular insults, MDM2 rather fosters podocyte demise by driving the podocytes into mitosis, pushing them to bypass the G2/M checkpoint that is, mitotic catastrophe. ${ }^{8}$ Moreover, by facilitating the NF-KB signaling, MDM2 promotes glomerular inflammation in injured glomeruli and thus further aggravates the podocyte loss, endothelial damage and glomerulosclerosis. ${ }^{9}$ In acute tubular injury MDM2 exacerbates the initial damage phase via NF-kB-related inflammation but promotes regeneration in the later healing phase via p53 regulation. ${ }^{10}$ In podocyte homeostasis MDM2 functions as a crucial factor protecting podocytes from p53 overactivation related cell death contributing thus to the lifelong survival of podocytes. ${ }^{11}$ Resting tubular epithelial cells express high levels of MDM2 and we hypothesized that quiescent tubular epithelial cells require MDM2 to maintain the homeostasis. To address this hypothesis we depleted the MDM2 or both MDM2 and p53 in cultured murine tubular epithelial cells and in primary tubule cells and in the mouse model by generating the tubular epithelial cells-specific knockouts.

\section{Results}

MDM2 prevents tubular epithelial cell death in vitro. The knockdown (KD) of MDM2 in mouse tubular epithelial cell line with siRNA resulted in decreased viability of tubular cells in

\footnotetext{
${ }^{1}$ Nephrologisches Zentrum, Medizinische Klinik und Poliklinik IV, Klinikum der LMU München, Munich, Germany; ${ }^{2}$ Department of Anatomy and Cell Biology, LudwigMaximilians Universität, Munich, Germany; ${ }^{3}$ Pathology \& Immunology \& Internal Medicine (Renal), Washington University, School of Medicine, St Louis, MO, USA; ${ }^{4}$ Department of Anatomy and Cell Biology, Universitätsmedizin Greifswald, Greifswald, Germany and ${ }^{5}$ Department of Anatomy and Histology, Faculty of Veterinary Medicine, Assiut University, Assiut, Egypt

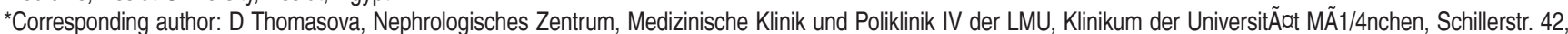
München D-80336, Germany. Tel: +4989218075880; Fax: +4989218075860; E-mail: dana.thomasova@med.uni-muenchen.de

Received 29.7.16; revised 21.10.16; accepted 25.10.16; Edited by U Moll
} 
comparison to tubular cells treated with control siRNA (Figure 1a). MDM2 suppression was associated with a marked increase in p53 and p53 effector genes p21 and
PUMA transcript levels (Supplementary Figure 1A). The concomitant KD of MDM2 and p53 significantly improved the viability of tubular epithelial cells in vitro (Figure 1a).
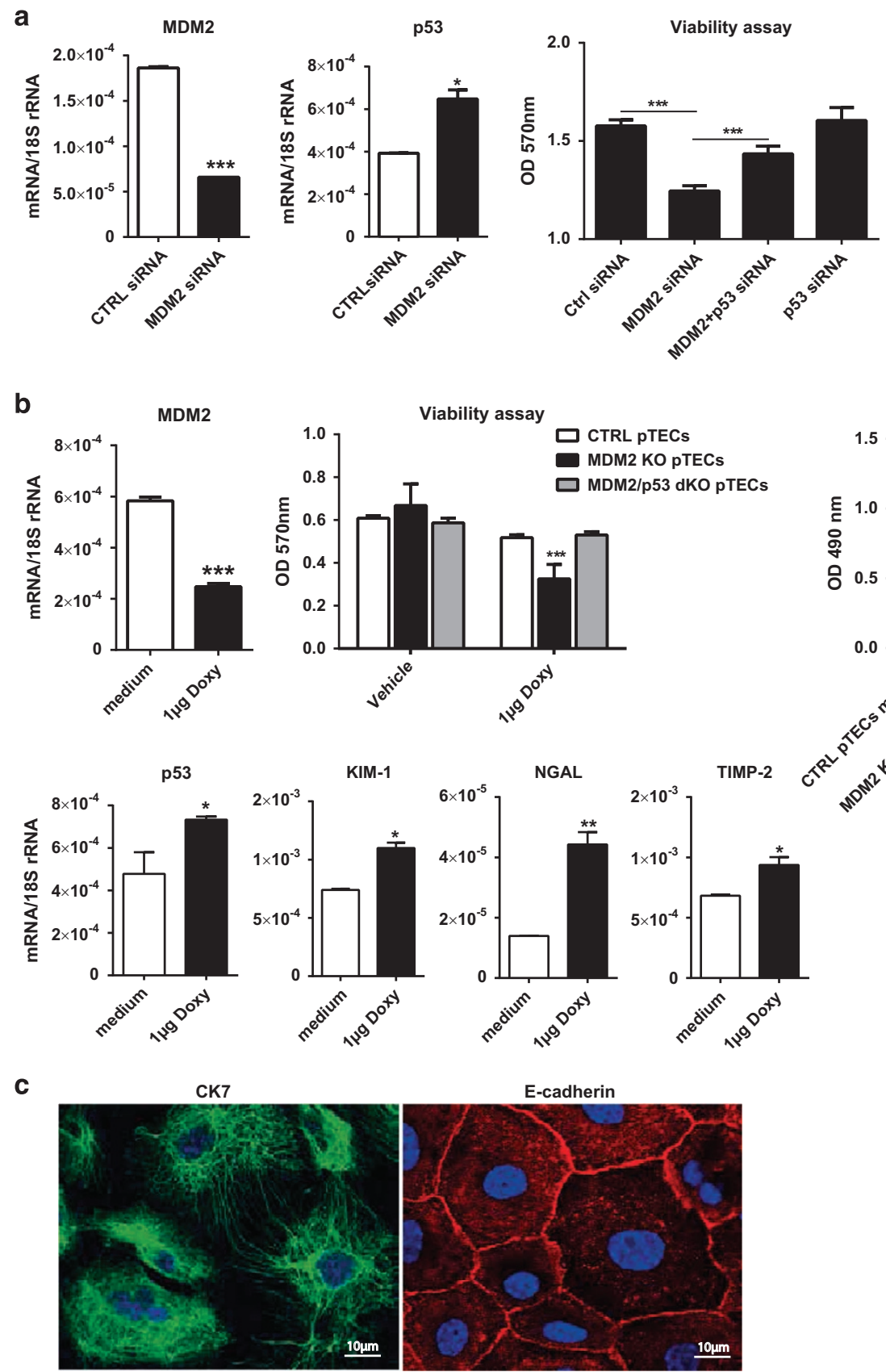

d

CTRL PTECs

Pax8creMDM2f/f pTECs

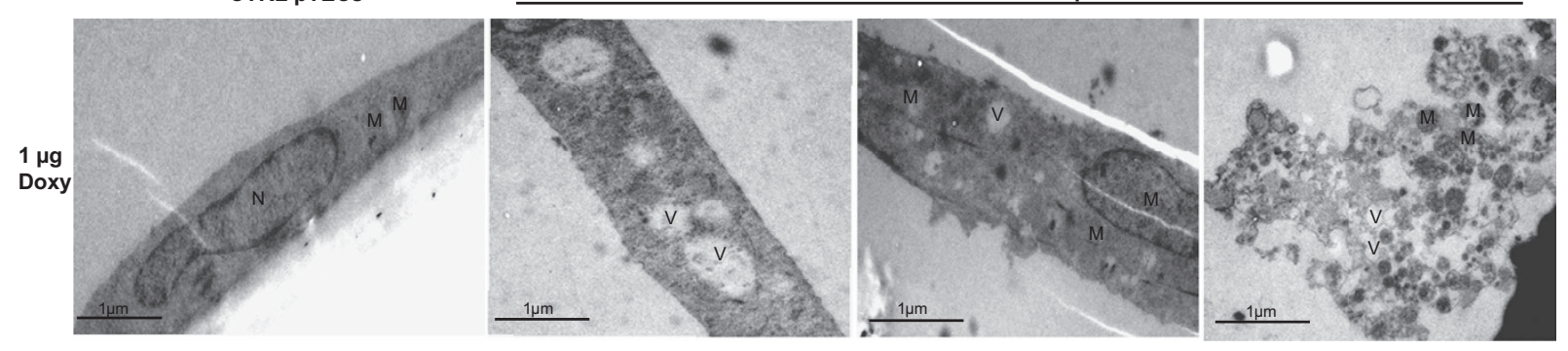


This result was confirmed in primary tubular cells MDM2 KO pTECs isolated from Pax8rtTa-cre; MDM2f/f mice, where MDM2 was depleted specifically in tubular epithelial cells in vitro by treatment with doxycycline. The generation of theses mice is described below. MDM2 mRNA levels decreased significantly in MDM2 KO pTECs treated with $1 \mu \mathrm{g}$ doxycycline (Figure 1b). The Mdm2-deficient primary tubular cells showed increased expression of tubular damage markers KIM-1, NGAL and TIMP-2 as well as increased cell death, due to the upregulation of p53 (Figure 1b). Increased p53 activity was confirmed by elevated mRNA expression of p53-target genes p21 and PUMA (Supplementary Figure 1B). The simultaneous depletion of MDM2 and p53 completely rescued the viability of the primary tubular cells (Figure 1b). The pTECs population was about $95 \%$ pure as assessed by staining for the tubular epithelial cell markers cytokeratin-7 and E-cadherin (Figure 1c). To prove the specificity of MDM2 depletion in tubular epithelial cells, we isolated also parietal epithelial and mesangial cells from kidneys of Pax8rtTA-cre; $M D M 2 f / f$, treated them with doxycycline, and checked mRNA levels of MDM2 and viability of those cells. Unlike in primary tubular cells, MDM2 expression and viability remained unchanged in the glomerular cells in comparison to the controls (Supplementary Figure 1C). Ultrastructural analysis of murine primary tubular cells lacking MDM2 revealed vacuolization of cytoplasm, nicks in the cytoplasmic membrane, and eventually cell death with complete disassembly of the cell structure (Figure 1d). These results suggest that MDM2 is required to protect the tubular cells from p53 overexpression-related cell death.

Mdm2 KD in zebrafish larvae induces cell death of renal tubular epithelial cells. To validate the in vitro results in vivo, a KD of mdm2 was generated in zebrafish larvae by the injection of specific morpholinos into fertilized eggs and was confirmed by qRT-PCR (Figure 2a). At 4 days post fertilization (d.p.f.), the mdm2 KD zebrafish larvae developed pericardial edema (white arrow in Figure 2b), a hallmark of kidney failure, in contrast to control morpholino-injected larvae (Ctrl) and larvae with a double KD knockout of mdm2 and p53 (mdm2/p53). For a rapid screening of the glomerular filtration barrier function, we used the transgenic zebrafish strain $\mathrm{CADE}^{12}$ that expresses the eGFP-labeled protein of the albumin family $g c$ (group specific component) in the blood which is unable to pass the healthy filtration barrier. In Figure $2 \mathrm{~b}$, it is shown that the $\mathrm{KD}$ of $\mathrm{mdm} 2$ resulted in larvae with reduced eGFP fluorescence in the vessels indicating a leakage of the filtration barrier. To investigate the morphology of pronephric tubules after the KD of $\mathrm{mdm} 2$, we used the zebrafish strain $\mathrm{Tg}(w t 1 b$ :eGFP) that expresses eGFP in podocytes, parietal epithelial cells and proximal tubule cells. ${ }^{13}$ Sections of zebrafish larvae revealed a significant dilatation of the pronephric tubules in mam2 KD larvae (Figure 2c) which could be rescued to some extent by the KD of p53. Additionally, we have found less epithelial cells in the proximal tubules after the mdm2 KD compared with Ctrl and $\mathrm{mdm} 2 / \mathrm{p} 53 \mathrm{KD}$ larvae (Figure 2c). The TUNEL assay demonstrated that this is due to an increase of dead cells in mdm2 KD larvae (Figure 2d). Furthermore, the remaining cells showed a reduced expression of the $\mathrm{Na}^{+}-\mathrm{K}^{+}-$ATPase, a marker of differentiated tubular epithelial cells (Figure $2 \mathrm{c}$ ).

In vivo imaging of the pronephros of living $\mathrm{Tg}(\mathrm{wt} 1 \mathrm{~b}$ :eGFP) larvae by two-photon microscopy (2-PM) confirmed the significant dilatation of the Bowman space after mdm2 KD (asterisk in Figure 2e; Supplementary Movie 1) in contrast to mdm2/p53 and Ctrl KD larvae (Supplementary Movies 2 and 3). We have found that the maximum width of the pronephric proximal tubules in living zebrafish larvae significantly increased from $7.03 \mu \mathrm{m}$ (S.E.M. $=2.29 \mu \mathrm{m}, n=7$ ) in Ctrl and $8.53 \mu \mathrm{m}$ (S.E.M. $=2.19 \mu \mathrm{m}, n=7, P=0.01)$ in $\mathrm{mdm} 2 /$ p53 KD larvae to $14.67 \mu \mathrm{m}$ (S.E.M. $=2.42 \mu \mathrm{m}, \quad n=9$, $P=0.044$ ) in mdm2 KD larvae (Figure 2f). These results show that $\mathrm{mdm} 2$ is essential for pronephric tubular epithelial cells by protecting them from a p53-dependent cell death.

MDM2 depletion in tubular epithelium results in acute kidney injury. To confirm these findings in the mammalian kidney, we crossed Pax8rtTA-cre mice with MDM2f/f mice to generate a mice model with inducible MDM2 deletion exclusively in renal tubular epithelial cell upon doxycycline treatment, Pax8rtTA-cre;MDM2f/f (Figure 3a). These mice were born at expected Mendelian ratios and did not show any functional or renal histological abnormalities within 6 months of age. Real-time PCR analysis of kidney extracts from Pax8rtTA-cre;MDM2f/f mice treated with doxycycline (MDM2 $^{-/- \text {tubulus) }}$ for 4,8 or 11 days demonstrated progressively declining levels of MDM2 mRNA compared with control mice (Figure 3b). MDM2 immunostaining was selectively diminished in the renal tubular cells of the Pax8rtTA-cre; MDM2f/f mice treated with doxycycline $\left(\mathrm{MDM}^{-/-t u b u l u s}\right)$ while the MDM2 immunostaining remained intact in the glomerulus, confirming thus the selectivity of the MDM2 tubular deletion (Figure 3c; Supplementary Figure 2A). $\mathrm{MDM}^{-/-t u b u l u s}$ mice showed progressive impairment of kidney function in comparison to control mice, as documented by significant increase of plasma creatinine and blood

Figure 1 MDM2 knockdown/knockout in murine tubular cell line and in primary tubular cells. (a) Murine tubular epithelial cells were incubated for $24 \mathrm{~h}$ with MDM2 siRNA or control scrambled siRNA and MDM2 and p53 mRNA expression was measured by RT-PCR. The viability was assessed by MTT assay. (b) Primary tubular epithelial cells (pTEC) were isolated from Pax8-rtTAcre;MDM2f/f (MDM2KO pTECs) or Pax8-rtTAcre;MDM2fff;p53ff/ (MDM2/p53dKO pTECs) mice and treated with doxycycline to induce MDM2 or MDM2/p53 knockout. mRNA expression of MDM2, p53 and tubular damage markers KIM-1, NGAL and TIMP-2 was determined by RT-PCR. Cell viability and cell death were measured by MTT and LDH assays. CTRL pTECs were isolated from MDM2fl/fl mice. CTRL pTECs treated with $2 \%$ Triton X were used as positive control. (c) Representative confocal microscopy pictures of pTECs stained for markers of tubular epithelial cells cytokeratine-7 and E-cadherin used to assess the purity of the cell isolates. (d) Electron microscopy images of control and MDM2KO pTECs treated with doxycycline. The MDM2-depleted pTECs undergo cell death associated with prominent cytoplasmic vacuolization, cell membrane breaks and finally with the complete disassembly of the cell structure. All experiments were performed in triplicate. Data are means \pm S.E.M. ${ }^{*} P<0.05,{ }^{* *} P<0.01,{ }^{* * *} P<0.005$. N, nucleus; $\mathrm{M}$, mitochondria; V, vacuole 
urea nitrogen (BUN) levels (Figure 3d). Measured glomerular filtration rate (GFR) declined from day 4 of doxycycline treatment in $\mathrm{MDM}^{-/- \text {tubulus }}$ mice and at day 8 the mice were severely oliguric compared with control littermates (Figure $3 e$ ). The decline of $\mathrm{MDM}^{-/-t u b u l u s}$ mice kidney function was also associated with the shortened lifespan
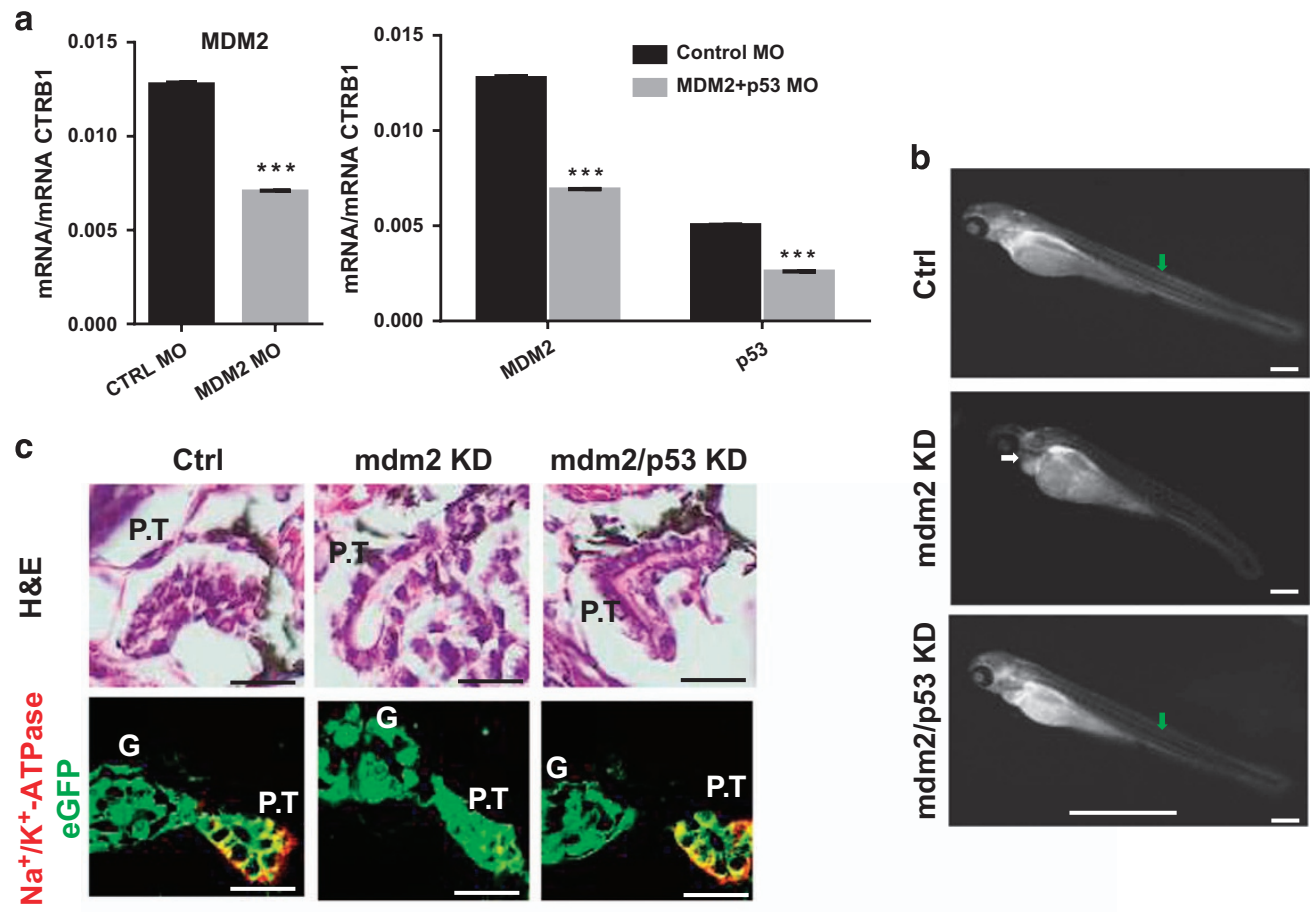

mdm2 KD
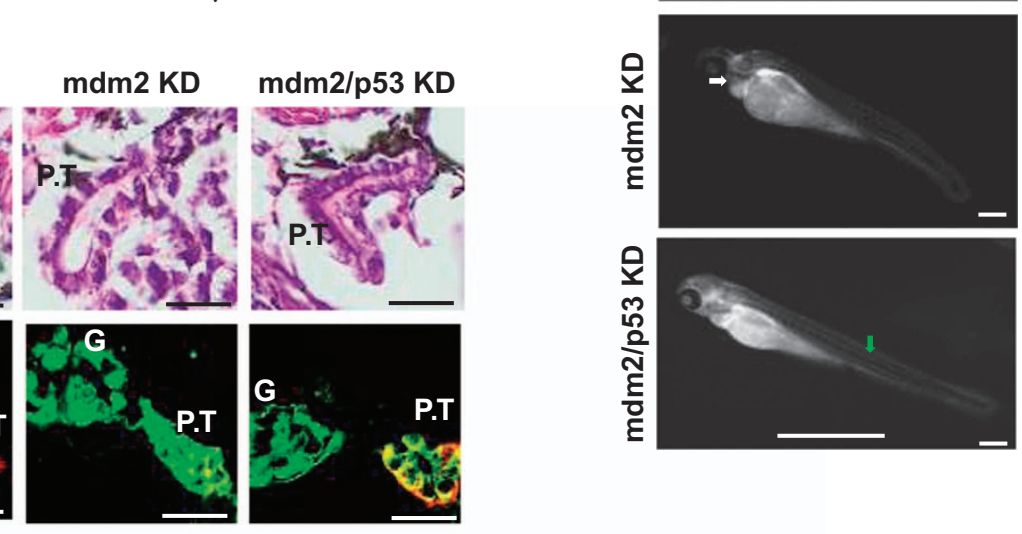

d

Ctrl
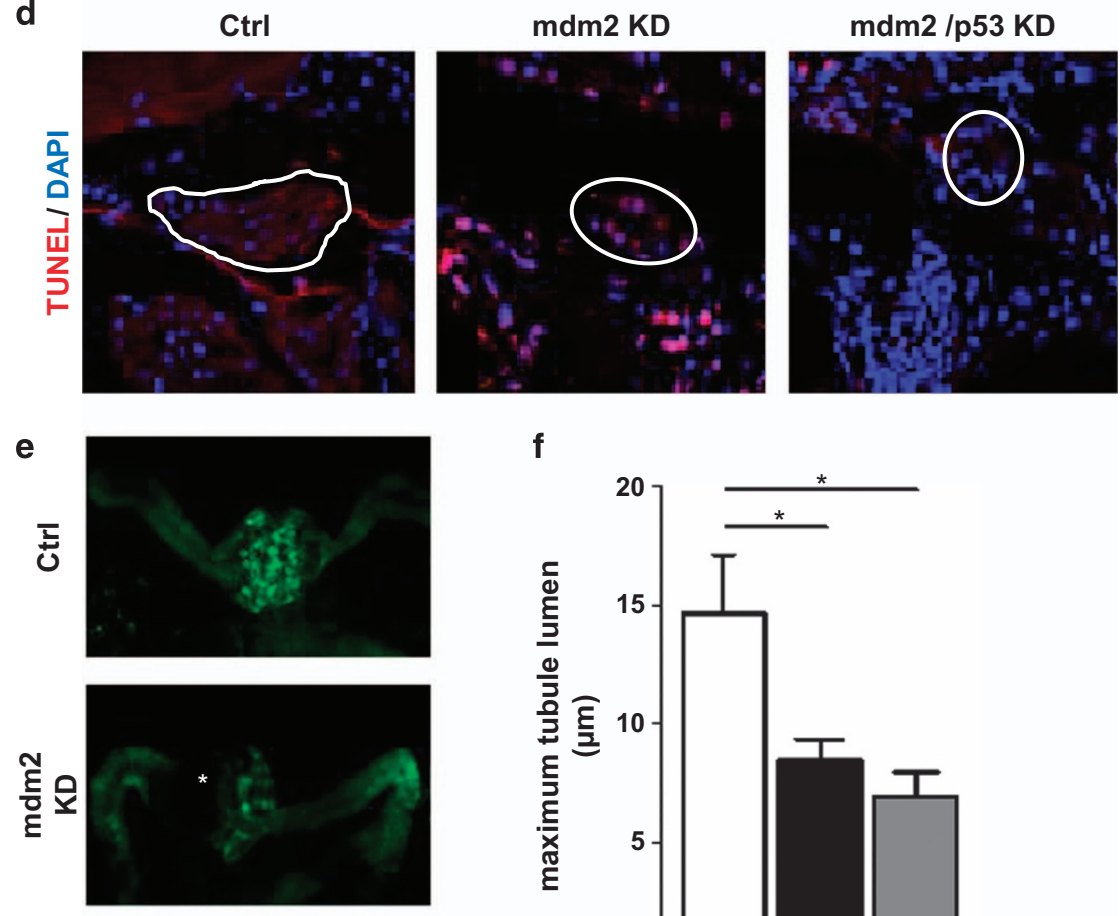

f
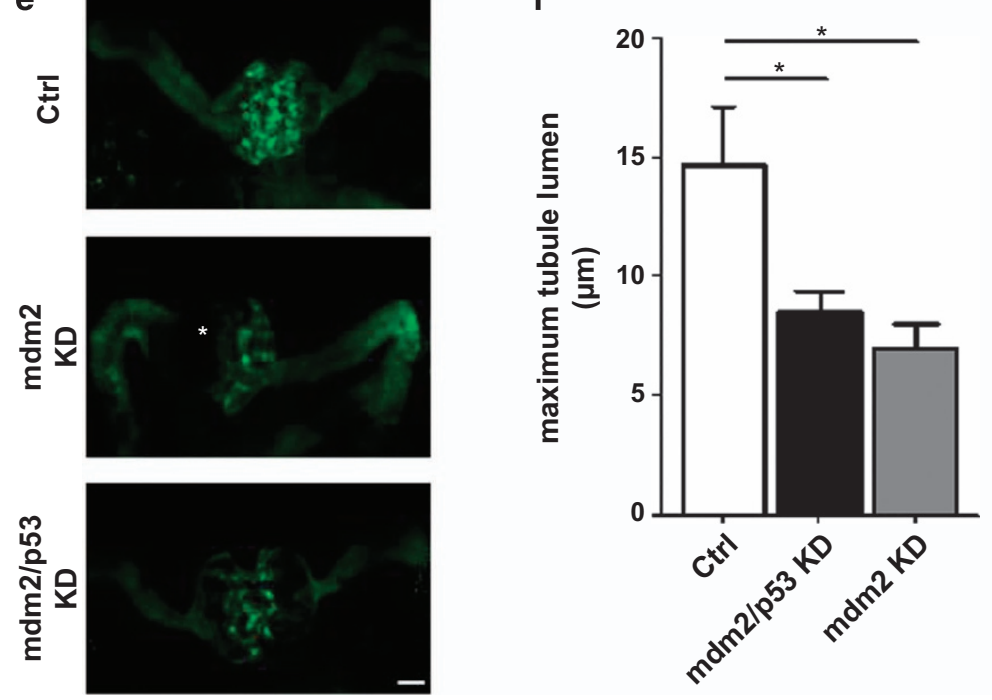
(Figure 3e). Also the renal mRNA levels of p53 and its effector genes p21 and PUMA and tubular damage markers KIM-1, NGAL and TIMP-2 had increased with the length of doxycycline treatment (Figure 3f; Supplementary Figure 2B). On light microscopy the kidneys of $\mathrm{MDM}^{-/ \text {-tubulus }}$ mice appeared normal at 4 days of doxycycline treatment while on day 8 profound tubular epithelial cells swelling and their vacuolization were apparent (Figure 4a). At day 11 of the doxy treatment the kidneys displayed massive tubular dilation with tubular cell flattening, damage and cell loss and multifocal tubular granular casts (Figure 4a). Although the MDM2 deletion in tubular epithelial cells affected both proximal and distal tubuli as well as collecting ducts, the proximal tubuli exhibited the highest damage with the loss of almost $80 \%$ of the proximal tubular cells as determined by staining for Lotus tetragonolobus lectin (Figure 4b). Analysis of the kidneys of $\mathrm{MDM}^{-/-t u b u l u s}$ mice by electron microscopy detected ultrastructural abnormalities in tubular epithelial cells such as swelling of the cytoplasm, endoplasmic reticulum changes, swelling of the mitochondria with the loss of cristae and their transformation in the vacuoles (Figure 5a). The nuclei were edematous but with no membrane rupture and they did not appear to have consolidated chromatin (Figure 5a). These abnormalities suggest that the tubular epithelial cells undergo a stage of asphyxia and start dying from the cytoplasm with dead mitochondria. Eventually, the tubular epithelial cells completely disintegrate, the plasma membrane ruptures, and the nuclei are released together with other cytoplasmic organelles (Figure 5a). Lack of MDM2 in tubular epithelial cells was associated with the progressive increase of p53 expression and its nuclear shift. Simultaneously we observed also the Ki-67 activation, suggesting the hypertrophy or proliferation of undamaged tubular epithelial cells with incomplete MDM2 deletion or of the tubular progenitors (Supplementary Figure 3A). Nevertheless, the regenerating tubular cells were not able to compensate for the cellular loss due to p53 overactivation. TUNEL as well as cleaved caspase-3 staining showed just marginal caspase-3 activation in the tubular compartment, mostly in the kidneys with marked p53 upregulation and massive tubular cell death (Figure 5b; Supplementary Figure 3B). The caspase-3 activation level does not correspond to the extent of the kidney damage and is suggestive of secondary cell apoptosis. We conclude that MDM2 is essential for tubular epithelial cells homeostasis and survival and prevents acute kidney injury.
The MDM2 deleterious phenotype in tubular epithelium is p53 dependent. To test for the role of p53 in the structural and functional renal pathology of $\mathrm{MDM}^{-/- \text {tubulus }}$ mice, we generated inducible tubular epithelial cell-specific simultaneous MDM2 and p53 knockout mice MDM2/p53 ${ }^{\text {dKO }}$ tubulus and the littermate controls with one p53 allele intact MDM2 $2^{-/-t u b u l u s} / \mathrm{p} 53^{\text {wt/fl }}$. We treated the both mouse lines with doxycycline to induce the deletion of the respective gene alleles. The analysis of the functional and histological parameters of the mice models confirmed that the depletion of 553 rescues the pathological phenotype of the $\mathrm{MDM}^{-/- \text {tubulus }}$ mice (Figures $6 \mathrm{a}-\mathrm{e}$ ).

Tubular epithelium compensates only partially for the cell loss caused by MDM2 depletion. Previously, it was reported that mice lacking Mdm2 in the intestinal epithelium can fully compensate for the MDM2 depletion/p53 activationmediated cellular loss because of negative selection of the MDM2 transgenic cells and rapid proliferation and overgrowth of cells with insufficient Cre recombinase activity and thus incomplete MDM2 depletion. ${ }^{14}$ To investigate whether this phenomenon occurs also in renal tubular epithelium, which is known for its fast regenerative capacity, we subjected the Pax8rtTA-cre; MDM2f/f mice to different doxycycline treatment regimens to avoid the rapid lethality of the continuous doxycycline treatment. We treated the mice with doxycycline for 2 days to deplete the MDM2 just in the portion of the tubular epithelial cells and repeated the treatment after 5 days of recovery for three times. The renal function of the experimental mice was impaired compared with the control mice as documented by elevated serum creatinine and BUN levels (Figure 7a) but the lifespan of the experimental animals was not affected (data not shown). The histological analysis showed focal tubular damage with overproduction of extracellular matrix, suggesting that the loss of tubular cells is only partially recovered by surviving tubular cells but rather mesenchymal repair occurs (Figure 7b). Masson trichrome staining confirmed the accumulation of the fibrotic tissue in the kidneys of experimental mice (Figure 7b) and also mRNA expression levels of several pro-fibrotic genes were elevated (Figure 7c). We detected moderate p53 activation with nuclear shift throughout the tubular compartment with especially high expression in medullar region of the kidney (Figure 7b). We conclude that unlike intestinal epithelium, tubular epithelial cells cannot completely compensate for the cells lost due to the MDM2 deletion.

Figure 2 Mdm2 knockdown in zebrafish larvae. (a) After the treatment of fertilized zebrafish eggs with mdm2 MO, mdm2/p53MO, mRNA expressions of mdm2 or both mdm2 and p53 were significantly reduced in contrast to larvae treated with Ctrl MO. The target mRNA expression levels were determined by real-time RT-PCR and expressed as mean of the ratio versus the respective ctrb1 mRNA level \pm S.E.M. Data are means \pm S.E.M. ${ }^{\star \star \star} P<0.005$. (b) CADE larvae developed pericardial edema (white arrow) after the mdm2 $\mathrm{KD}$ in contrast to control morpholino-injected larvae (Ctrl) and mdm2/p53 morpholino-injected larvae. Mdm2 KD larvae showed a loss of the vascular eGFP fluorescence (green arrow) due to a leaky filtration barrier. Scale bar represents $50 \mu \mathrm{m}$. (c) Paraffin sections were stained with H\&E and an antibody against Na $/ \mathrm{K}^{+}-\mathrm{ATPase}$, respectively. Glomerulus (G), proximal tubule (P.T). Scale bar represents $20 \mu \mathrm{m}$. (d) TUNEL assay showed dead cells in the pronephric tubules of mdm2 KD larvae. Scale bar represents $20 \mu \mathrm{m}$. (e) $3 \mathrm{D}$ reconstructions of 2-PM z-stack showed dilated pronephric proximal tubules in mdm2 KD larva. Scale bar represents $20 \mu \mathrm{m}$. (f) The box plot histogram shows the significant dilatation of pronephros proximal tubule lumen of mdm2 KD larvae compared with Ctrl and mdm2/p53 KD larvae. Scale bar $20 \mu \mathrm{m}$ 


\section{Discussion}

We hypothesized that MDM2 is important for homeostasis of resting tubular epithelial cells in kidney. In the cell culture experiments the tubular epithelial cells lacking MDM2 showed decreased viability. The mouse model with the specific deletion of MDM2 in tubular epithelial cells displayed shortened lifespan, fast decline in renal function as a
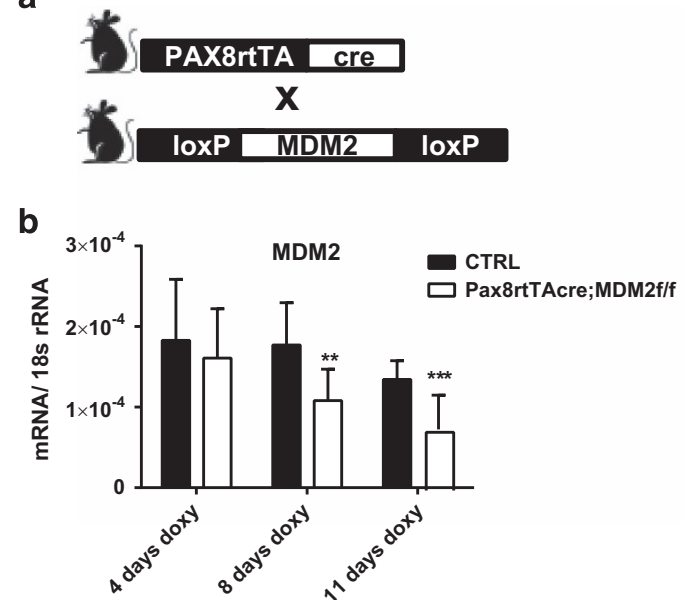

d
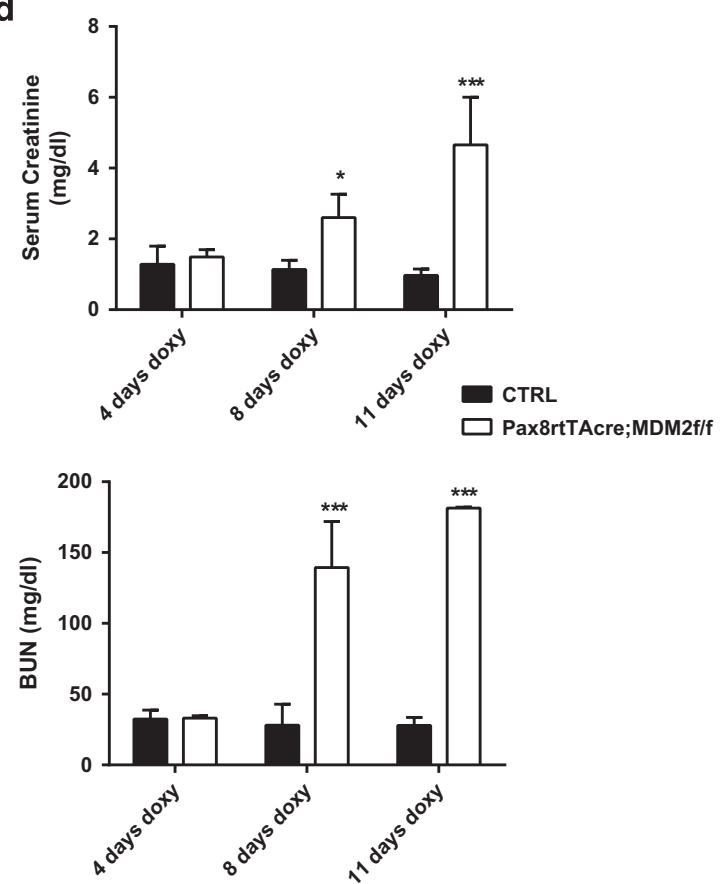
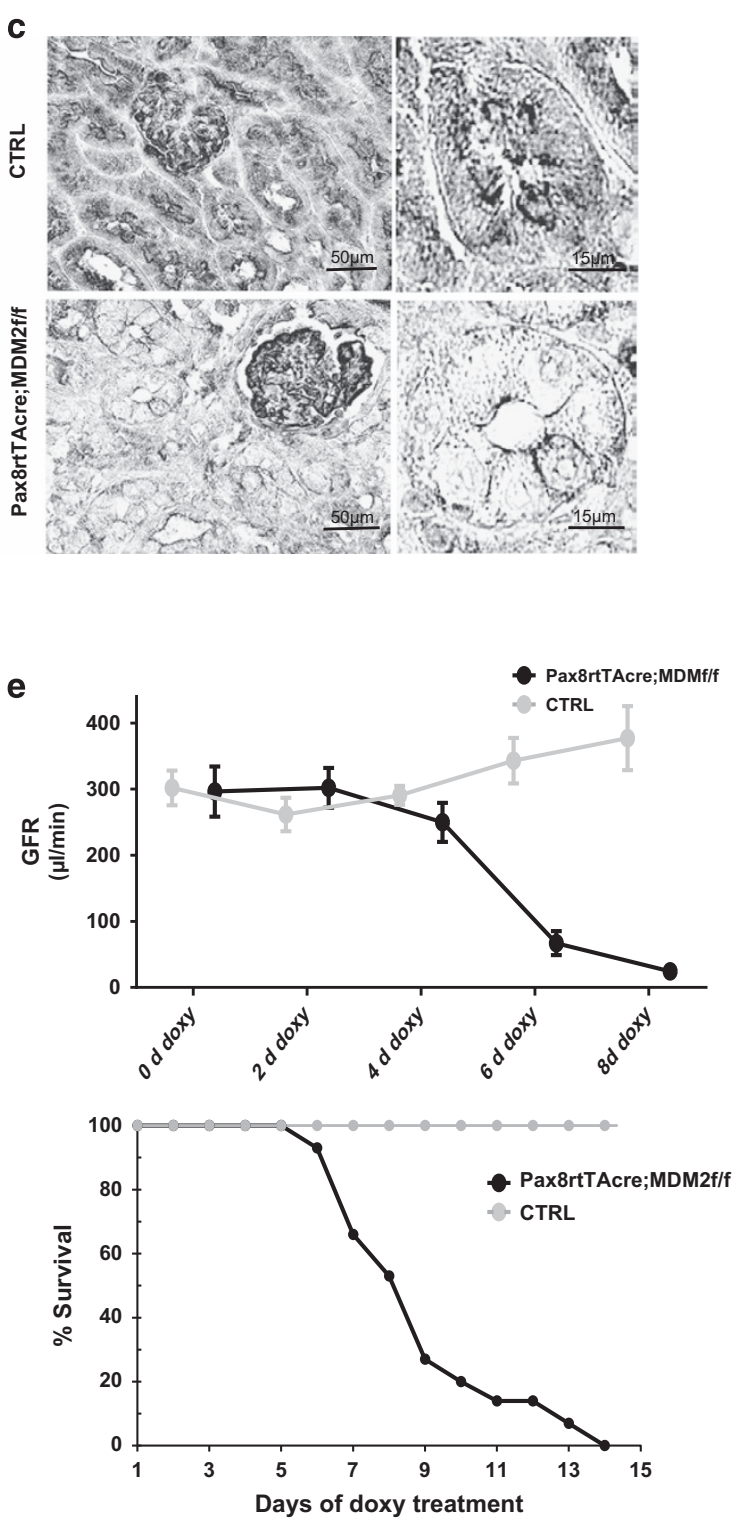

f
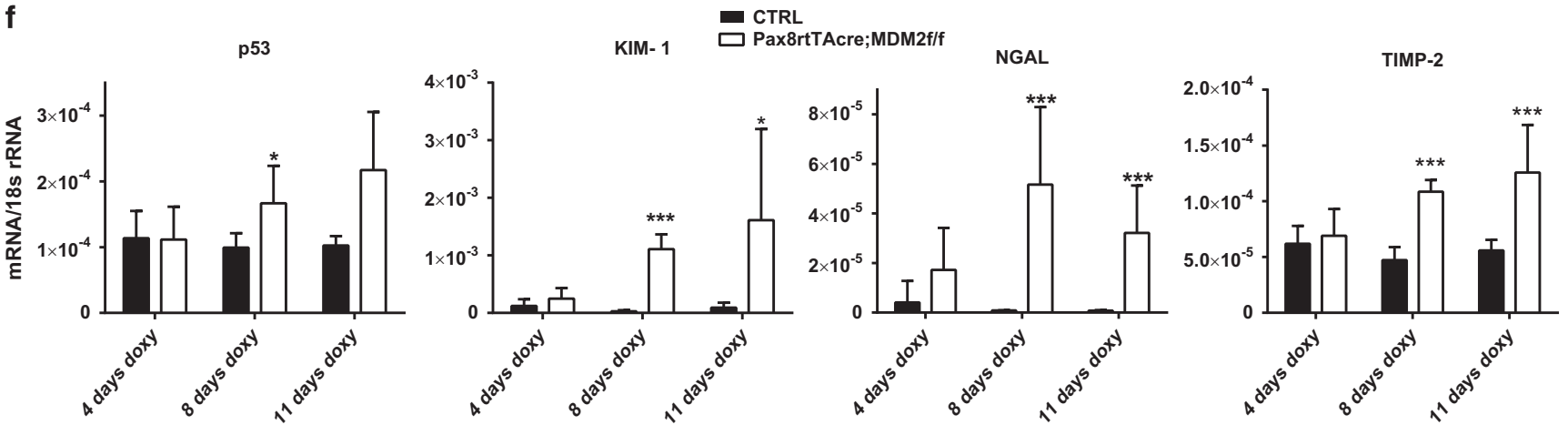
documented by reduced GFR and increased plasma creatinine and BUN. We also detected significant upregulation of tubular damage markers and massive swelling, mitochondrial degeneration and cell death in the tubular compartment in the kidneys of the experimental animals. All these changes developed in unchallenged kidney and were consistent with acute tubular injury. The tubular epithelium was not able to fully compensate for the cell loss due to the MDM2 depletion by proliferation of remaining tubular cells with intact MDM2 but rather mesenchymal healing with fibrosis occurred. The pathological phenotype was completely rescued by co-deletion of p53. We conclude that MDM2 is essential for survival and homeostasis of intact tubular cells in healthy kidney.

MDM2, the main negative regulator of p53 suppresses its function in three different ways; it chaperons p53 out of the nucleus, that is, out of the transcriptional centrum, it blocks the transcription of p53 effector genes and it ubiquitinates p53 and targets it for proteasomal degradation. ${ }^{4}$ Through the p53 inhibition, MDM2 fosters cell proliferation and prevents p53mediated cell death, cell cycle arrest and senescence. ${ }^{15}$ This MDM2 function is indispensable for the embryonic development, wound healing and regeneration ${ }^{16}$ but it also facilitates autoimmune disorders, such as lupus erythematosus ${ }^{17}$ and carcinogenesis. ${ }^{18,19}$ MDM2 is overexpressed frequently in many human tumors, especially in breast cancer and sarcomas. $^{20}$ The inhibitors of MDM2 and p53 binding are being currently tested in clinical trials as potential cancer therapy. ${ }^{21,22}$ Nevertheless also MDM2 depletion has deleterious effects as documented by embryonic lethality of a mouse model with genetic-deletion of MDM2. The mouse embryos die due to the uncontrolled p53-dependent cell death, while p53 deficiency completely rescues this deleterious phenotype. ${ }^{23,24}$ Specific deletion of MDM2 in developing kidney results in impairment of renal progenitor cell expansion, in aberrant nephrogenesis and differentiation and leads to hypodysplasia of the kidneys. ${ }^{25-27}$ Our data are in line with these studies and show that MDM2 is crucial for the survival and homeostasis of unchallenged tubular epithelial cells in kidney. MDM2 prevents p53-mediated cell death of these renal cells. Our findings differ from a study which showed that unbuffered p53 activity caused by MDM2 deletion is detrimental only in radiosensitive tissues due to the massive cell loss, while the radio-insensitive tissues, including kidney, are protected from cell death but exhibit inhibition of cell proliferation. $^{28}$ Our data indicate that MDM2 depletion in tubular epithelial cells leads to massive cell death due to p53 overactivation but proliferation activity is maintained as documented by increased expression of Ki-67, marker of proliferation. Our results are corroborated by another study showing that global MDM2 deletion results in morphological and functional abnormalities in both radiosensitive and radioinsensitive tissues, including kidney. ${ }^{14}$ Renal phenotype included initially just mild damage with no aberrant functional effect, but subsequently the kidneys exhibited severe injury with impairment of renal function. ${ }^{14}$ Further on, MDM2 deletion in intestinal epithelial cells results in multiple intestinal abnormalities in newborn animals. ${ }^{29}$ These abnormalities completely disappeared in adulthood due to the selection against the enterocytes lacking MDM2 and increased proliferation of the epithelium with intact MDM2. ${ }^{29}$ Although the renal tubular epithelium has an extensive regenerative capacity, our findings indicate that in kidneys of tubular specific depleted MDM2 mice the complete epithelial healing does not occur and is compensated by mesenchymal healing with extensive fibrosis. This suggests that the inhibition of MDM2 could lead to acute kidney injury and due to incomplete healing contribute to development of chronic kidney disease. ${ }^{30}$ In our previous studies we showed that MDM2 in acute kidney injury promotes tubular injury in early postischemic phase via augmentation of NF-kB signaling and thus inflammation in p53-independent manner. ${ }^{10}$ Our present data document, that all renal anomalies due to MDM2 depletion in unchallenged tubular epithelial cells are dependent on p53 activity, as the defects completely disappeared when p53 was absent. This is in line with studies which showed dose-dependent attenuation of tubular cell death and kidney injury in mouse model of cisplatin induced nephrotoxicity treated with p53 siRNA or with chemical inhibitor of p53. ${ }^{31,32}$

Together, MDM2 is crucial in intact tubular epithelial cells in kidney to prevent spontaneous p53 overactivation dependent cell death and thus prevent acute tubular injury. As MDM2 antagonists are being developed as an alternative treatment to chemotherapy for cancer treatment, it is of note that MDM2 inhibition might be detrimental for normal tissues, especially for kidney as our data suggest. We conclude that MDM2 is essential for survival and homeostasis of tubular epithelium in kidney.

\begin{abstract}
Materials and Methods
Cell culture experiments. Murine tubular epithelial cells (mTECs cell line) were maintained in DMEM medium supplemented with $10 \%$ fetal bovine serum and $1 \%$ penicillin/streptomycin. The primary tubular cells (pTECs) were prepared from renal cell suspensions as previously described. ${ }^{33}$ In brief, 4 weeks old Pax8-rtTAcre; MDM2f/f or MDM2f/f control mice were used for renal cell extraction. Decapsulated kidneys were diced and digested in $1 \mathrm{mg} / \mathrm{ml}$ collagenase A (Roche Diagnostics, Mannheim, Germany) for $30 \mathrm{~min}$ at $37^{\circ} \mathrm{C}$ and then passed through $70 \mu \mathrm{m}$ pore sieve (BD, Franklin Lakes, NJ, USA), washed, and diluted in $2 \mathrm{ml}$ of PBS. Separation of the tubular segments was achieved through Percoll $(31 \%)$
\end{abstract}

Figure 3 Tubular cell-specific MDM2 knockout in mouse model results in acute kidney injury with fast decline of renal function. (a) Mice expressing inducible cre recombinase under control of Pax8 promoter were crossed with MDM2 $2^{\text {f/f/t }}$ mice to generate tubular cell-specific MDM2 knockout mice. (b) RT-PCR analysis confirmed suppression of MDM2 mRNA expression in kidney lysates of Pax8rtTA-cre;MDM2f/f mice treated with doxycycline. (c) Immunohistochemical staining confirmed MDM2 deletion in tubular cells while in podocytes in glomerulus the MDM2 expression remained unchanged. (d) Pax8rtTA-cre;MDM2f/f mice treated with doxycycline developed increasing elevation of plasma creatinine and plasma BUN ( $n=5-6$ mice in each group). (e) Left: GFR measurement showed significant decrease of GFR from day 6 of doxycycline treatment in Pax8rtTA-cre

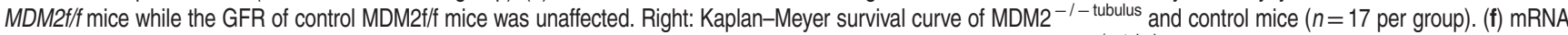
expression of $\mathrm{p} 53$ as well as of tubules damage markers KIM-1, NGAL and TIMP-2 was increasingly elevated in MDM2 $2^{-/ \text {tubulus }}$ mice kidneys in comparison to control mice kidneys. Data are means \pm S.E.M. ${ }^{*} P<0.05,{ }^{* *} P<0.01,{ }^{* * *} P<0.005$ 

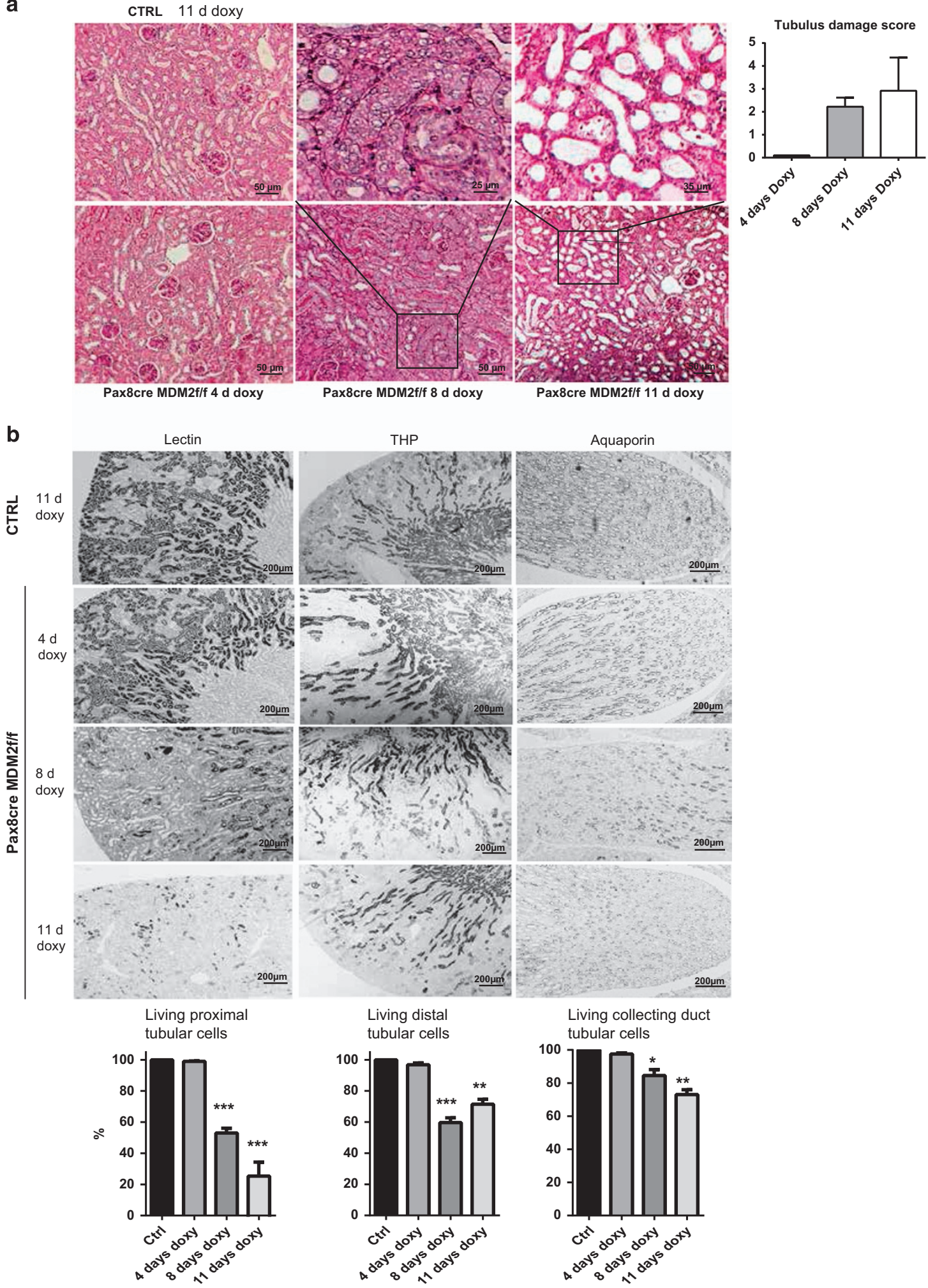

Figure 4 Tubular injury in tubular cell-specific MDM2 knockout mice kidneys. (a) Representative images of PAS-stained kidney sections at a magnification 200x from Pax8rtTA-cre;MDM2f/f and control mice treated for 4, 8 or 11 days with doxycycline showing the progressive aggravation of tubular injury. At day 4 was no tubular damage apparent, at day 8 the tubular cells swelling and vacuolization were the prominent pathologic features and at day 11 the global tubular damage with massive cell loss, tubular dilation and tubular casts was detected. Tubular injury was quantified on PAS-stained renal section as described in Materials and methods. (b) Lotus tetragonolobus lectin staining identified proximal tubuli, Tamm-Horsfall protein (THP) staining identified distal tubuli and Aquaporin 2 identified the collecting ducts in Pax8rtTA-cre;MDM2f/f and control mice kidneys treated for 4,8 or 11 days with doxycycline. The quantitative assessment of tubuli with intact staining patterns is shown for each staining. Data are means \pm S.E.M. from six mice in each group. ${ }^{*} P<0.05,{ }^{* *} P<0.01,{ }^{* \star *} P<0.005$. All images are shown at a magnification of $\times 100$ 
a
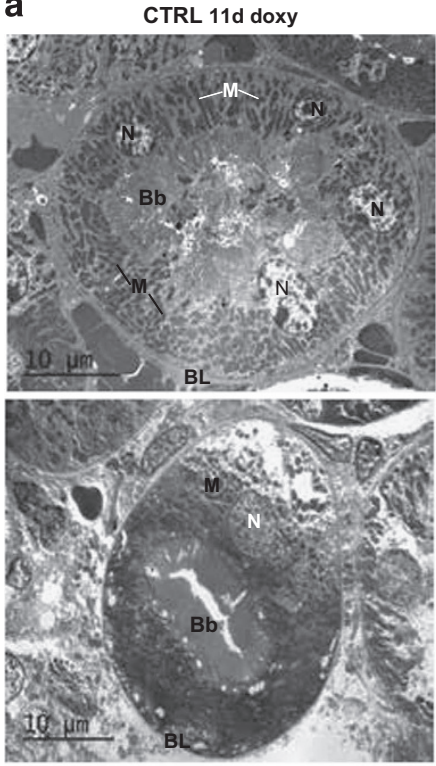

Pax8cre MDM2f/f 4d doxy
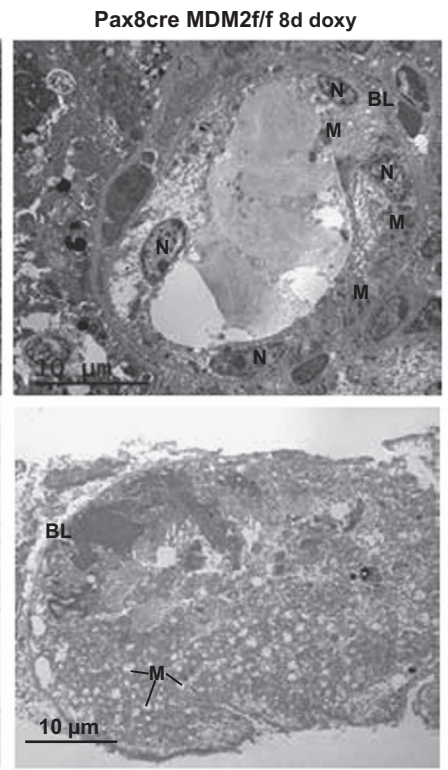

Pax8cre MDM2f/f 11d doxy
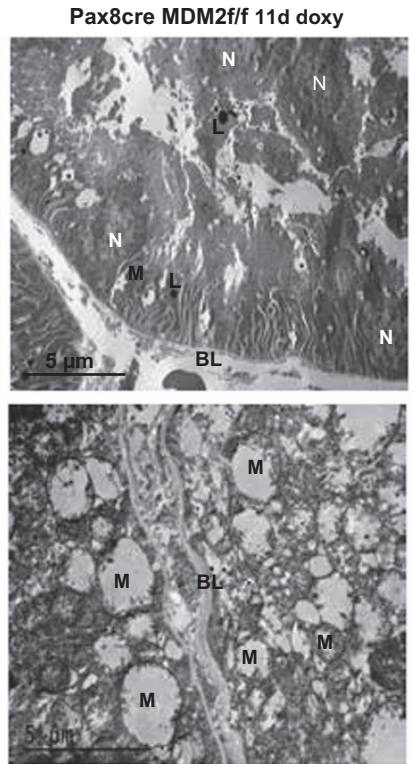

Pax8cre MDM2f/f 11d doxy

b

Casp 3

Ki 67
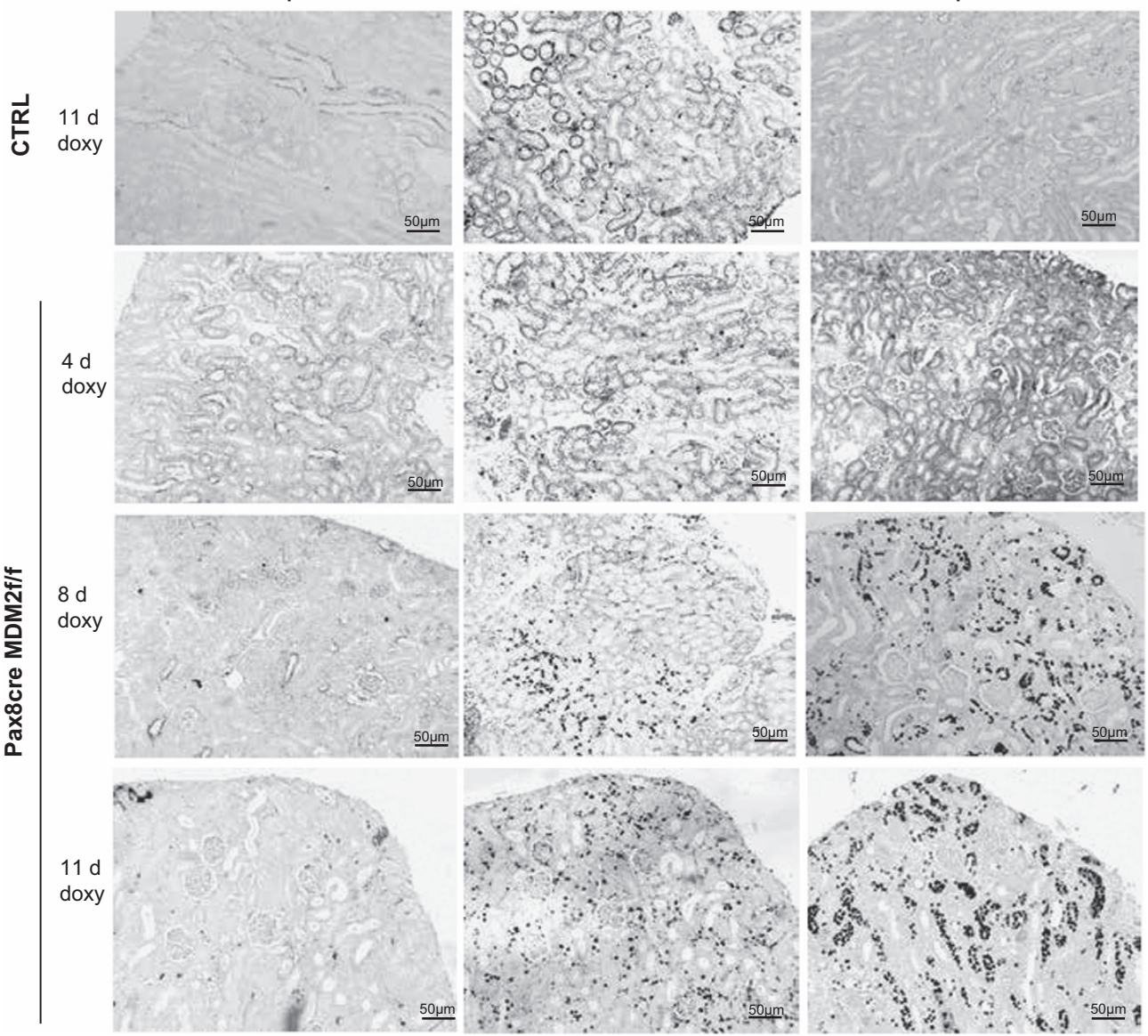

Figure 5 Ultrastructural pathology in tubular cell-specific MDM2 knockout mice tubular cells. (a) Electron microscopy at 4 days of MDM2 depletion reveled an onset of cytoplasmic swelling, at 8 days pronounced cytoplasmic swelling with occasional cytoplasmic membrane rupture but intact nuclei and at 11 days a complete degradation of the tubular cell structure with vacuolization of swollen cytoplasm, massive degeneration of mitochondria, edematous nuclei and release of the cell content into the tubular lumen. (EM in successive low-medium-high 1500-12 000 magnification). (b) Representative pictures of kidney sections from Pax8rtTA-cre;MDM2f/f and control mice kidneys treated for 4, 8 or 11 days with doxycycline showing staining for activated caspase-3, marker of apoptosis, Ki-67, marker of proliferation or hypertrophy and p53, marker of the cell cycle arrest, senescence and cell death. All images are shown at a magnification of $\times 100$. Bb, brush border; BL, basal lamina; L, lysosome; M, mitochondria; N, nucleus 
a
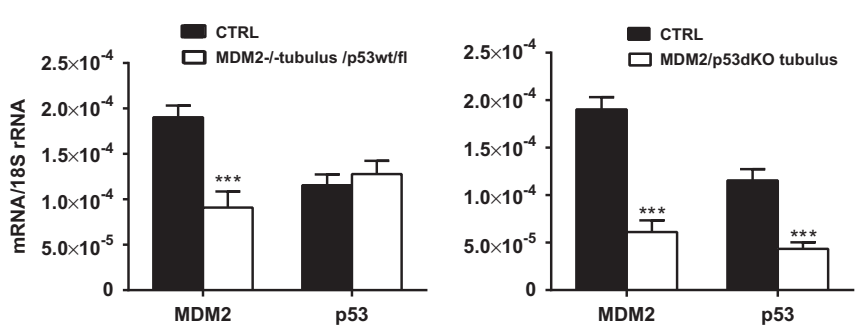

b

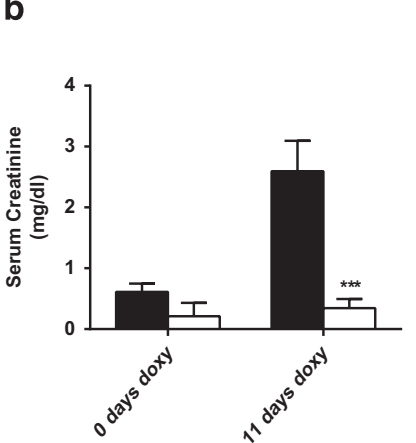

d

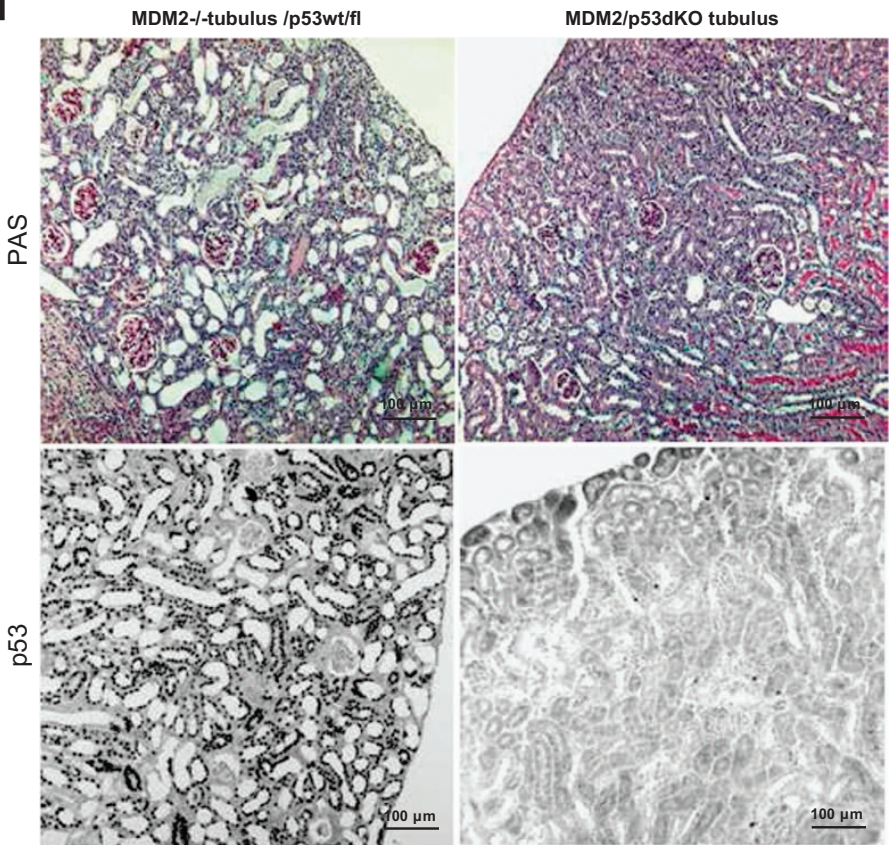

MDM2/p53dKo tubulus

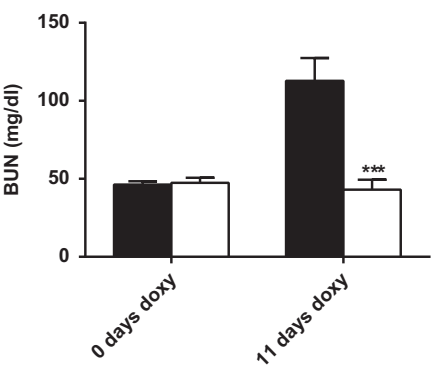

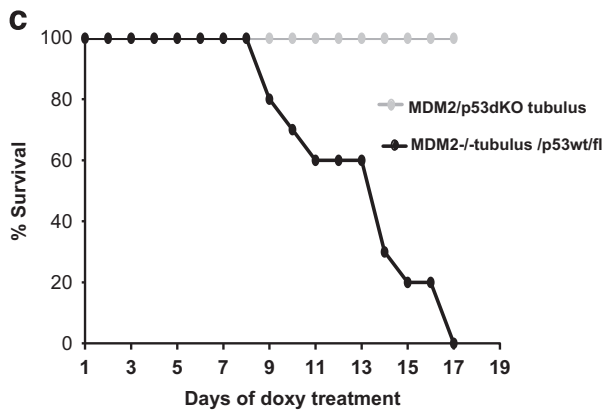

Days of doxy treatment
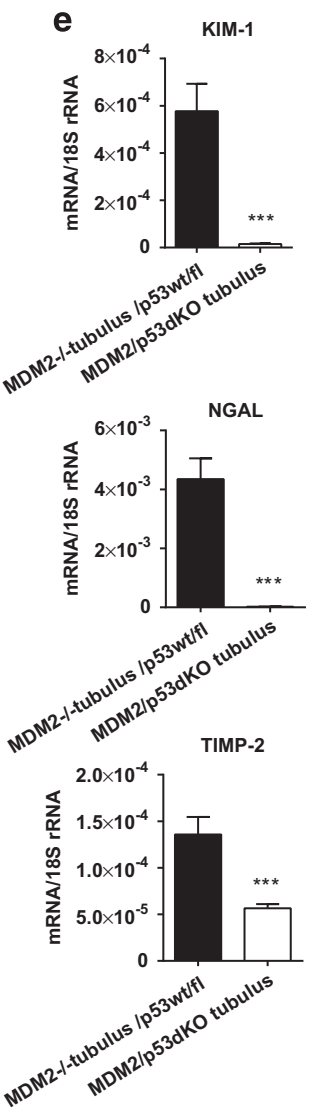

Figure 6 Simultaneous MDM2 and p53 tubular cell-specific knockout rescues the pathological phenotype in MDM2/p53 ${ }^{\mathrm{dKO}}$ tubulus mouse model. (a) Total mRNA was prepared from kidneys isolated from MDM2 ${ }^{-1-\text { tubulus }} / \mathrm{p} 53^{\text {wtfflo }}$ or MDM2/p53 $3^{\text {dKO tubulus }}$ mice respectively and control MDM2 $2^{\text {fl/ti }}$ mice treated for 11 days with doxycyclin. The target mRNA expression levels were determined by real-time PCR and expressed as mean of the ratio versus the respective $18 S$ mRNA level \pm S.E.M. (b) Serum creatinine and BUN measurement in plasma of MDM2/p53 ${ }^{\mathrm{dKO}}$ tubulus and positive control MDM2 ${ }^{-1-\text { tubulus }} / \mathrm{p} 53^{\text {wttl }}$ mice treated for 11 days by doxycycline $(n=10$ in each group). (c) Kaplan-Meyer survival curve of MDM2/p53 $3^{\mathrm{dkO} \text { tubulus }}$ and control MDM2 $2^{-/ \text {-tubulus }} / \mathrm{p} 53^{\text {wttf }}$ mice $(n=10$ in each group). (d) Representative images of PAS and p53 stained kidney sections from MDM2/p53 $3^{\text {dKO tubulus }}$ and control MDM2 ${ }^{-1-\text { tubulus }} / \mathrm{p} 53^{\text {wttil }}$ mice treated for 11 days with doxycycline. All images are shown at a magnification of $\times 200$. (e) Real-time PCR analysis of renal tubular damage markers KIM-1, NGAL and TIMP-2 mRNA prepared from kidneys isolated from MDM2/p53 $3^{\text {dKO tubulus }}$ and positive control MDM2 ${ }^{-1-\text { tubulus }} / \mathrm{p} 53^{\text {wtt }}$ mice treated for 11 days with doxycycline. Data are means \pm S.E.M. ${ }^{* \star *} P<0.005$ 
a

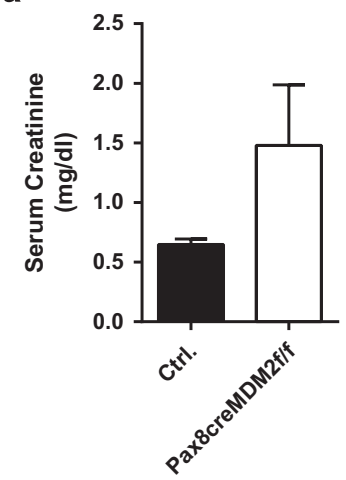

b
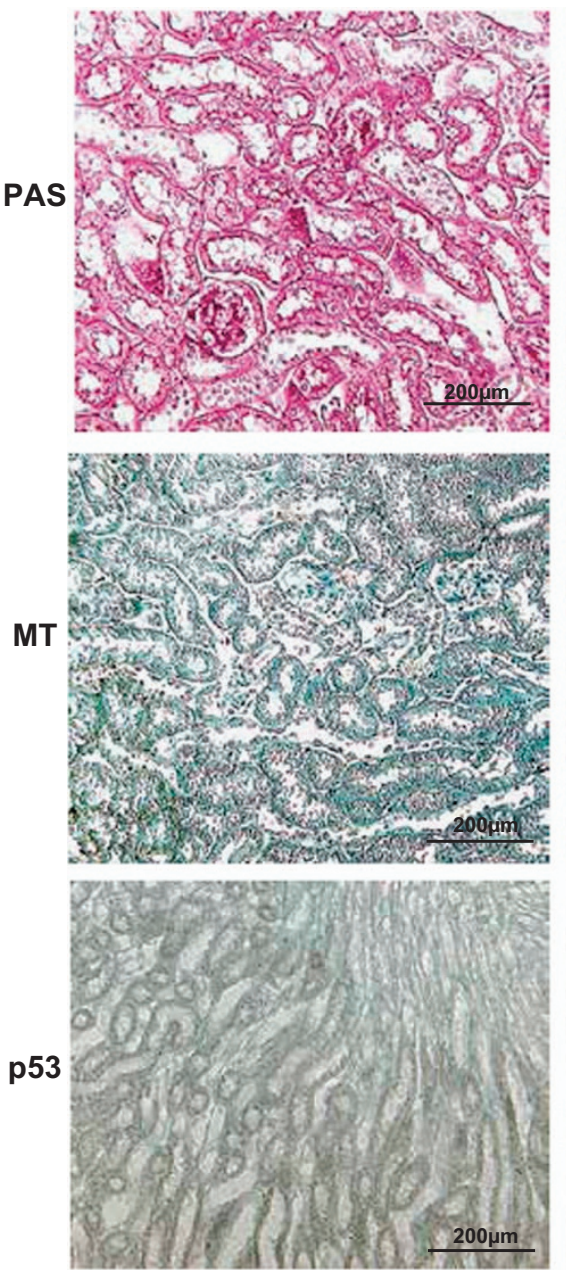

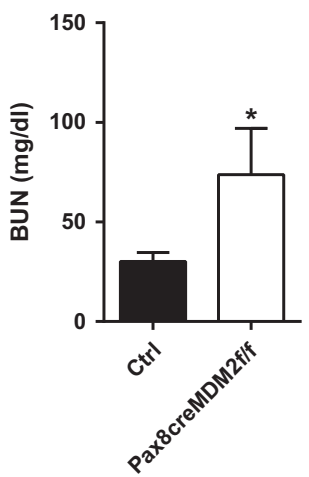

Pax8rtTAcre;MDM2f/f
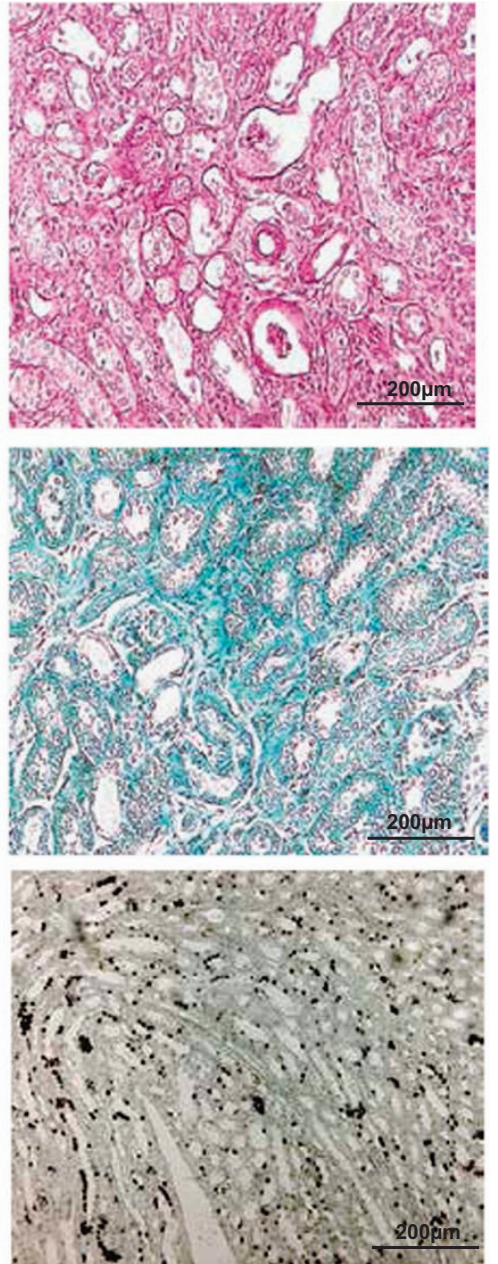
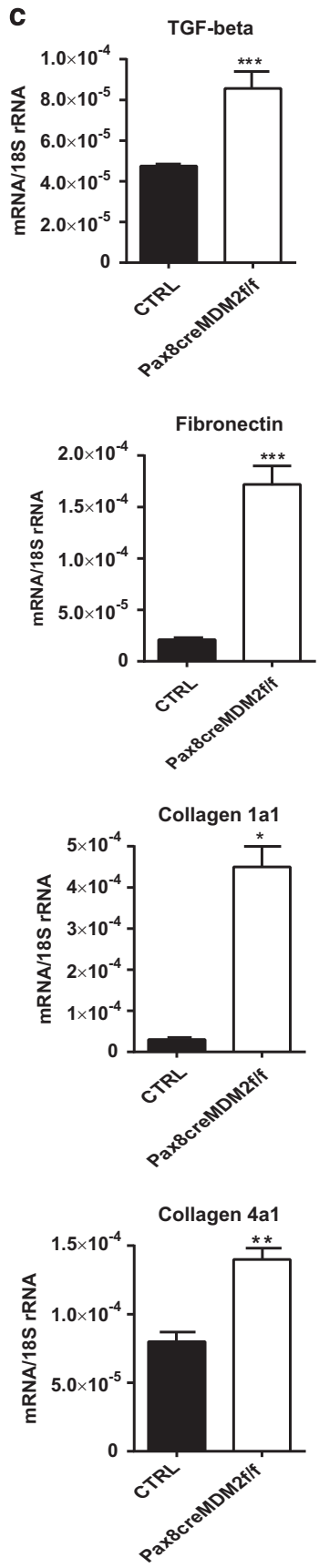

Figure 7 Tubular epithelium compensates only partially for the cell loss caused by MDM2 depletion. To induce a sub-lethal deletion of MDM2 in tubular epithelial cells in our mouse kidney model we treated Pax8rtTA-cre;MDM2f/f mice intermittently with $2 \mathrm{mg} / \mathrm{ml}$ doxycycline for 4 weeks. (a) Pax8rtTA-cre;MDM2f/fmice treated with intermittent regimen of doxycycline had elevated plasma creatinine and plasma BUN at 4 weeks ( $n=5-6$ mice in each group). (b) Representative images of kidney sections from control MDM2f/fand Pax8rtTA-cre;MDM2f/f mice treated for 4 weeks intermittently with doxycycline and stained with PAS, Masson trichrome and p53 antibody. All images are shown at a magnification of $\times 200$. (c) Real-time PCR analysis of pro-fibrotic genes mRNA prepared from kidneys isolated from experimental and control mice treated for 4 weeks with doxycycline. Data are means \pm S.E.M. ${ }^{\star} P<0.05,{ }^{\star \star} P<0.01,{ }^{* \star \star} P<0.005$

centrifugation at 3000 r.p.m. $/ 10 \mathrm{~min} / 4^{\circ} \mathrm{C}$. The pellet of tubular segments was collected and washed twice with PBS at 1500 r.p.m. $/ 5 \mathrm{~min} / 4^{\circ} \mathrm{C}$. The renal tubular cell isolates were cultured under sterile conditions at $37^{\circ} \mathrm{C}$ and $5 \% \mathrm{CO}_{2}$ in conditioned medium consisting of DMEM w/glucose (Gibco/Life Technologies,
Grand Island, NY, USA), 10\% fetal bovine serum (Biochrom, Berlin, Germany), 1\% penicillin/streptomycin (PAA Laboratories, Pasching, Austria), HBSS (Sigma-Aldrich, Steinheim, Germany), HEPES (Gibco/Life Technologies, Grand Island, NY, USA), EGF, T3, hydrocortisone, PGE-1 and insulin transferrin sodium selenite supplement 
Table 1 Primers used for real-time RT-PCR

\begin{tabular}{|c|c|c|}
\hline Target & Primer sequence & \\
\hline MDM2 & $\begin{array}{l}\text { Forward primer } \\
\text { Reverse primer }\end{array}$ & $\begin{array}{l}\text { 5'-TGTGAAGGAGCACAGGAAAA -3' } \\
5^{\prime}-\text { TCCTTCAGATCACTCCCACC -3' }\end{array}$ \\
\hline p53 & $\begin{array}{l}\text { Forward primer } \\
\text { Reverse primer }\end{array}$ & $\begin{array}{l}\text { 5'-TCCGACTGTGACTCCTCCAT-3' } \\
5^{\prime} \text {-CTAGCATTCAGGCCCTCATC-3' }\end{array}$ \\
\hline KIM-1 & $\begin{array}{l}\text { Forward primer } \\
\text { Reverse primer }\end{array}$ & $\begin{array}{l}\text { 5'-TGGTTGCCTTCCGTGTCTCT-3' } \\
\text { 5'-TCAGCTCGGGAATGCACAA-3' }\end{array}$ \\
\hline NGAL & $\begin{array}{l}\text { Forward primer } \\
\text { Reverse primer }\end{array}$ & $\begin{array}{l}\text { 5'-TGAACTTCTGAAAACGGCT-3' } \\
\text { 5'-AGCAGCAAGGGCACAAT-3'3' }\end{array}$ \\
\hline TIMP-2 & $\begin{array}{l}\text { Forward primer } \\
\text { Reverse primer }\end{array}$ & $\begin{array}{l}\text { 5'-CGTTTTGCAATGCAGACGTA-3' } \\
\text { 5'-GAATCCTCTTGATGGGGTTG-3' }\end{array}$ \\
\hline TGF- $\beta$ & $\begin{array}{l}\text { Forward primer } \\
\text { Reverse primer }\end{array}$ & $\begin{array}{l}\text { 5'-GGAGAGCCCTGGATACCAAC-3' } \\
\text { 5'-CAACCCAGGTCCTTCCTAAA-3' }\end{array}$ \\
\hline Fibronectin & $\begin{array}{l}\text { Forward primer } \\
\text { Reverse primer }\end{array}$ & $\begin{array}{l}\text { 5'-GGAGTGGCACTGTCAACCTC-3' } \\
\text { 5'-ACTGGATGGGGTGGGAAT-3' }\end{array}$ \\
\hline Collagen1a1 & $\begin{array}{l}\text { Forward primer } \\
\text { Reverse primer }\end{array}$ & $\begin{array}{l}\text { 5'-ACATGTTCAGCTTTGTGGACC-3' } \\
\text { 5'-TAGGCCATTGTGTATGCAGC-3' }\end{array}$ \\
\hline Collagen4a1 & $\begin{array}{l}\text { Forward primer } \\
\text { Reverse primer }\end{array}$ & $\begin{array}{l}\text { 5'-GTCTGGCTTCTGCTGCTCTT-3' } \\
\text { 5'-CACATTTTCCACAGCCAGAG-3' }\end{array}$ \\
\hline $18 s$ & $\begin{array}{l}\text { Forward primer } \\
\text { Reverse primer }\end{array}$ & $\begin{array}{l}\text { 5'-GCAATTATTCCCCATGAACG-3' } \\
\text { 5'-AGGGCCTCACTAAACCATCC- 3' }\end{array}$ \\
\hline
\end{tabular}

(Roche Diagnostics, Mannheim, Germany). For the assessment of the purity of the pTECs population were the cells grown in the 8-well chamber slides to confluency, than fixed in ice-cold acetone, stained for the markers of the tubular epithelial cells cytokeratin-7 and E-cadherin and TOPRO for nuclei and analyzed with confocal microscopy. For the viability assays, the mouse mTECs or primary TECs were seeded in 96 well plates ( 8000 cells/well), for the RNA extraction the mTECs and pTECs were cultured in 6-well plates $(200000$ cells/wellThe mTECs were then incubated with $25 \mathrm{nM}$ siRNA for 24-48 h using Lipofectamine RNAiMAX transfection reagent (Life Technologies, Darmstadt, Germany) for transient transfection. Specific siRNA to silence selectively MDM2 or p53 as well as appropriate control siRNA (Negative control No.1) was purchased from Ambion (Life Technologies). The pTECs isolated from Pax8-rtTAcre;MDM2f/f or MDM2f/f control mice were treated for $48 \mathrm{~h}$ with $1 \mu \mathrm{g} / \mathrm{ml}$ doxycycline to induce MDM2 depletion. The TECs or the PTECs were collected, $24-48 \mathrm{~h}$ post-treatment for RNA isolation or for cytotoxicity/viability assays that were performed using LDH assay (Cytotoxicity Detection Kit (LDH), Roche, Mannheim, Germany) and MTT assay (CellTiter 96 Non-Radioactive Cell Proliferation Assay, Promega, Madison, WI, USA) according to manufacturer's instructions. Experiments were performed in triplicate.

Zebrafish experiments:. Zebrafish strains and larvae were maintained as described previously. ${ }^{34}$ The following zebrafish strains were used: CADE ( $\operatorname{Tg}\left(-3.5\right.$ fabp10a:gc-eGFP) mitfa ${ }^{\text {w2/w2 }}$; roy ${ }^{\text {a9/ag }}$ ) which expresses a gc-eGFP fusion protein in the blood plasma. ${ }^{12}$ The (Tg(wt1b:eGFP)) strain that expresses eGFP under control of the wt $1 \mathrm{~b}$ promotor. ${ }^{13}$ The following morpholinos were used: mdm2 MO: 5'-AACAACTCTCTGTTGCCATTTTGGT-3'; p53 MO: 5'-GCGCC ATTGCTTTGCAAGAATTG-3'; Crtl MO: 5'-CCTCTTACCTCAGTTACAATTTATA-3'. MOs were diluted to a concentration of $0.3 \mathrm{nM}$. A volume of $\sim 3 \mathrm{nl}$ per zebrafish egg was injected into the yolk at the one- to four-cell stage using a microinjector (Transjector 5246; Eppendorf, Germany). For histological staining, we followed our previously published protocols. ${ }^{12}$ Anti-A6f antibody (1:25, Sigma-Aldrich) was used.

2-PM experiments: To prevent pigmentation, the zebrafish larvae were subjected to E3 medium supplemented with $0.003 \%$ phenylthiourea at 1 d.p.f. For in vivo imaging experiments, zebrafish larvae were embedded in $0.8 \%$ low-melting agarose (Biozym LE agarose, Germany) in E3 medium in a dorsal side up position. After hardening the larvae were covered with E3 medium supplemented with $0.06 \mathrm{mg} / \mathrm{m}$ Tricaine (Sigma-Aldrich, St Louis, MO, USA). All 2-PM experiments were performed at $22{ }^{\circ} \mathrm{C}$. Z-stacks of pronephric glomeruli and proximal tubules were recorded over a distance of $98 \mu \mathrm{m}$ with a voxel volume of $0.30 \times 0.30 \times 2 \mu \mathrm{m}$ and reconstructed as 3D movies using the ZEN 2010 software (Carl Zeiss Microimaging, Jena, Germany) as described before. ${ }^{35}$ For significance testing Gaussian distribution was checked by Kolmogorov-Smirnov testing, followed by significance testing with Student's $t$-test using SPSS V.22 (IBM, Armonk, NY, USA). P-values below 0.05 were declared as statistical significant. All experiments were performed in accordance with German animal protection law overseen by the agencies of the Federal State of Mecklenburg Western Pomerania.

Mouse experiments. The Pax8-rtTAcre;MDM2f/f mice were generated by breeding the MDM2 $2^{\text {floxflox }}$ mice, in which loxP sites flanked the exon 4 and 5 of MDM2 gene, with Pax8-rtTAcre mice, expressing the inducible Cre recombinase under control of the Pax8 promoter. The MDM2 ${ }^{\text {floxflox }}$ mice (/B6 mixed background) were a generous gift from G. Lozano (University of Texas, Huston, USA) and the Pax8-rtTA mice (C56B//6 background) were kindly provided by T. Huber (University of Freiburg, Freiburg, Germany). Both mice strains were previously described. ${ }^{36,37}$ The MDM2 $2^{\text {floxflox }}$ littermates lacking the Pax8-rtTAcre transgene were used as control mice. To generate the tubular epithelial cell-specific MDM2/p53 double knockout Pax8-rtTAcre;MDM2fff;p53f/f (MDM2/p53dKD tubulus) mice, we bred the Pax8-rtTAcre;MDM2f/f mice with $\mathrm{p5} 3^{\text {floxflox }}$ mice, in which the loxP sites were inserted in intron 1 and 10 to ensure Cre-mediated removal of nearly all coding sequences. ${ }^{38}$ The $\mathrm{p} 53^{\text {floxfllox }}$ mice were a generous gift from L. Rudolph (University of Ulm, Ulm, Germany). The Pax8-rtTAcre;MDM2ff;;p53wt/f (MDM2 ${ }^{-1-}$ tubulus/p53wtff) littermates were used as positive controls. To induce Cre recombinase expression, we treated the mice with $2 \mathrm{mg} / \mathrm{ml}$ doxycycline in drinking water supplemented with $5 \%$ sucrose for various number of days as indicated in figures. All animal studies were approved by the Committee on Research Animal Care, Regierungspräsidium Oberbayern.

Renal function measurement. Plasma creatinine levels as well as BUN (DiaSys GmBH, Holzheim, Germany) levels were determined using commercially available kits as per manufacturer's protocol.

GFR measurement. GFR was measured transcutaneously using a USB-device according to manufacturer's instructions (Mannheim Pharma\&Diagnostics $\mathrm{GmbH}$, Mannheim, Germany). The USB-device was fasten with adhesive tape to the shaved area on the mouse back. The mice were injected with FITC-Sinistrin i.v. (15 mg FITC-Sinistrin/100 g body weight). The measurement was performed for $60 \mathrm{~min}$ and analyzed with software provided by the manufacturer.

Renal histology, immunohistochemistry, confocal microscopy and electron microscopy. Kidney tissues were fixed in $4 \%$ neutral-buffered formalin, dehydrated in graded alcohols and embedded in paraffin. For routine histology the $4 \mu \mathrm{m}$ sections were stained with periodic acid-Schiff (PAS) reagent. For immunohistochemistry sections were deparaffinized, rehydrated, transferred into citrate buffer, and either autoclaved or microwave treated for antigen retrieval and processed as described. ${ }^{10}$ For histochemistry we used biotinylated Lotus Tetragonolobus Lectin stain (Vector Labs, Burlingame, CA, USA), Tamm-Horsfall 
protein stain (Santa Cruz, CA, USA) and rabbit anti-mouse Aquaporin 2 (Abcam, Cambridge, UK). Further on the following primary antibodies were used: rabbit anti-mouse MDM2 (Abcam, Cambridge, UK), rabbit anti-mouse p53 (Vector Laboratories, Burlingame, CA, USA), rat anti-mouse Ki-67 (DakoCytomation, Glostrup, Denmark), rabbit anti-mouse cleaved caspase-3 (Cell signaling Technology, Denvers, MA, USA), mouse anti-mouse E-cadherin (BD Biosciences, San Jose, CA, USA) and mouse anti-mouse cytokeratin-7 (Abcam). Immunofluorescent stainings were evaluated using a LSM 510 confocal microscope and LSM software (Carl Zeiss AG). For transmition electron microscopy, the kidney cortex was sectioned into $1 \times 1 \mathrm{~mm}$ cubes and immediately immersed in fixative containing $3 \%$ glutaraldehyde and $1 \%$ paraformaldehyde in PBS. Post-fixation kidneys were immersed in cold fixative containing $2 \%$ glutaraldehyde and $2 \%$ paraformaldehyde in sodium cacodylate buffer ( $\mathrm{pH} 7.4)$. Kidneys were postfixed in phosphate cacodylate-buffered $2 \%$ OhsO4 for $1 \mathrm{~h}$, dehydrated in graded ethanols with a final dehydration in propylene oxide and embedded in Embed-812 (Electron Microscopy Sciences, Hatfield, PA, USA). Ultrathin sections ( 90-nm thick) were stained with uranyl acetate and Venable's lead citrate and viewed with a JEOL model 1200EX electron microscope (JEOL, Tokyo, Japan).

Morphometry. To assess tubulointerstitial changes a semiquantitative score was established to evaluate the degree and extent of tubulointerstitial damage of each field and was graded from 0 to 4 as follows: 0 represents no lesion, 1 represents tubulointerstitial damage of less than $25 \%$ per field, and 2, 3 and 4 represent tubulointerstitial damage of $25-50 \%, 50-75 \%$ and more than $75 \%$ of the tubulointerstitium, respectively. Approximately 30 cortical and medullary visual fields $(20 x)$ per kidney were evaluated. Tubulointerstitial injury was defined by features such as tubular collapse, cast formation with tubular dilatation or atrophy, detachment of cells from the basement membrane.

RNA preparation and real-time quantitative PCR. Total RNA was extracted from mouse glomeruli, isolated using Dynabead perfusion, or murine podocyte cell line using Ambion RNA extraction kit (Invitrogen, Carlsbad, CA, USA) following the manufacturer's instructions. After quantification, RNA quality was assessed using agarose gels before reverse transcriptionwith Superscript II (Invitrogen) as described. ${ }^{39}$ Real-time RT-PCR was performed using SYBRGreen PCR master mix and analyzed with a Light Cycler 480 (Roche). All gene expression values were normalized using 18s RNA as a housekeeping gene. All primers used for amplification were from Metabion (Martinsried, Germany). Primers used are listed in the Table 1.

Statistical analysis. Values are expressed as mean \pm S.E.M. Statistical analysis was performed using Graphpad Prism5 software (GraphPad Software, La Jolla, CA, USA). Significance of differences was determined by the appropriate two-sided $t$-test for single comparisons. Analysis of variance (ANOVA) with post hoc Bonferroni's correction was used for multiple comparisons. $P$-values $<0.05$ were considered statistically significant.

\section{Conflict of Interest}

The authors declare no conflict of interest.

Acknowledgements. The work was supported by grants from the Deutsche Forschungsgemeinschaft (TH 1836/1-2 and AN372/11-2). We thank Dan Draganovici and Janina Mandelbaum for their expert technical assistance. This study was supported by a grant of the European Union within the 7th framework program (project 'EnVision', grant agreement no. 264143), by grants of the German Federal Ministry of Education and Research (BMBF) to N.E. (project 'STOP-FSGS', grant no. 01GM1518B) and by a scholarship of the Gerhard Domagk program of the University Medicine Greifswald to F.S.

1. Shankland SJ, Wolf G. Cell cycle regulatory proteins in renal disease: role in hypertrophy, proliferation, and apoptosis. Am J Physiol Renal Physiol 2000; 278: F515-F529.

2. Thomasova D, Anders HJ. Cell cycle control in the kidney. Nephrol Dial Transplant 2015; 30: 1622-1630.
3. Witzgall R. Are renal proximal tubular epithelial cells constantly prepared for an emergency? Focus on "the proliferation capacity of the renal proximal tubule involves the bulk of differentiated epithelial cells". Am J Physiol Cell Physiol 2008; 294: C1-C3.

4. Bond GL, Hu W, Levine AJ. MDM2 is a central node in the p53 pathway: 12 years and counting. Curr Cancer Drug Targets 2005; 5: 3-8.

5. Thomasova D, Mulay SR, Bruns H, Anders HJ. p53-independent roles of MDM2 in NF-kappaB signaling: implications for cancer therapy, wound healing, and autoimmune diseases. Neoplasia 2012; 14: 1097-1101.

6. Vousden KH, Lane DP. p53 in health and disease. Nat Rev Mol Cell Biol 2007; 8: 275-283.

7. Brown CJ, Lain S, Verma CS, Fersht AR, Lane DP. Awakening guardian angels: drugging the p53 pathway. Nat Rev Cancer 2009; 9: 862-873.

8. Mulay SR, Thomasova D, Ryu M, Kulkarni OP, Migliorini A, Bruns $\mathrm{H}$ et al. Podocyte loss involves MDM2-driven mitotic catastrophe. J Pathol 2013; 230: 322-335.

9. Mulay SR, Romoli S, Desai J, Honarpisheh MM, Kumar SV, Anders HJ et al. Murine double minute-2 inhibition ameliorates established crescentic glomerulonephritis. Am J Pathol 2016; 186: $1442-1453$.

10. Mulay SR, Thomasova D, Ryu M, Anders HJ. MDM2 (murine double minute-2) links inflammation and tubular cell healing during acute kidney injury in mice. Kidney Int 2012; 81 $1199-1211$.

11. Thomasova D, Bruns HA, Kretschmer V, Ebrahim M, Romoli S, Liapis H et al. Murine double minute-2 prevents $p 53-$ overactivation-related cell death (Podoptosis) of podocytes. J Am Soc Nephrol 2015; 26: 1513-1523.

12. Kotb AM, Simon O, Blumenthal A, Vogelgesang S, Dombrowski $F$, Amann $\mathrm{K}$ et al. Knockdown of ApoL1 in zebrafish larvae affects the glomerular filtration barrier and the expression of nephrin. PloS ONE 2016; 11: e0153768.

13. Bollig F, Perner B, Besenbeck B, Kothe S, Ebert C, Taudien S et al. A highly conserved retinoic acid responsive element controls wt1a expression in the zebrafish pronephros. Development 2009; 136: 2883-2892.

14. Zhang $Y$, Xiong S, Li Q, Hu S, Tashakori M, Van Pelt $C$ et al. Tissue-specific and age-dependent effects of global Mdm2 loss. J Pathol 2014; 233: 380-391.

15. Iwakuma T, Lozano G. MDM2, an introduction. Mol Cancer Res 2003; 1: 993-1000.

16. Ebrahim M, Mulay SR, Anders HJ, Thomasova D. MDM2 beyond cancer: podoptosis, development, inflammation, and tissue regeneration. Histol Histopathol 2015; 30: $1271-1282$

17. Allam R, Sayyed SG, Kulkarni OP, Lichtnekert J, Anders HJ. Mdm2 promotes systemic lupus erythematosus and lupus nephritis. J Am Soc Nephrol 2011; 22: 2016-2027.

18. Bohlman S, Manfredi JJ. p53-independent effects of Mdm2. In: Deb PS, Deb S (eds). Mutant p53 and MDM2 in Cancer. Springer: Dordrecht, Netherlands, 2014; 235-246.

19. Senturk E, Manfredi JJ. Mdm2 and tumorigenesis: evolving theories and unsolved mysteries. Genes Cancer 2012; 3: 192-198.

20. Deb SP. Cell cycle regulatory functions of the human oncoprotein MDM2. Mol Cancer Res 2003; 1: 1009-1016.

21. Kim ES, Shohet JM. Reactivation of p53 via MDM2 inhibition. Cell Death Dis 2015; 6: e1936.

22. Zhao Y, Aguilar A, Bernard D, Wang S. Small-molecule inhibitors of the MDM2-p53 proteinprotein interaction (MDM2 Inhibitors) in clinical trials for cancer treatment. J Med Chem 2015; 58: $1038-1052$.

23. Montes de Oca Luna R, Wagner DS, Lozano G. Rescue of early embryonic lethality in mdm2-deficient mice by deletion of p53. Nature 1995; 378: 203-206.

24. Jones SN, Roe AE, Donehower LA, Bradley A. Rescue of embryonic lethality in Mdm2deficient mice by absence of p53. Nature 1995; 378: 206-208.

25. Hilliard S, Aboudehen K, Yao X, El-Dahr SS. Tight regulation of p53 activity by Mdm2 is required for ureteric bud growth and branching. Dev Biol 2011; 353: 354-366.

26. Hilliard SA, Yao X, El-Dahr SS. Mdm2 is required for maintenance of the nephrogenic niche. Dev Biol 2014; 387: 1-14.

27. El-Dahr S, Hilliard S, Aboudehen K, Saifudeen Z. The MDM2-p53 pathway: multiple roles in kidney development. Pediatr Nephrol 2014; 29: 621-627.

28. Ringshausen I, O'Shea CC, Finch AJ, Swigart LB, Evan Gl. Mdm2 is critically and continuously required to suppress lethal p53 activity in vivo. Cancer Cell 2006; 10 . 501-514.

29. Valentin-Vega YA, Okano H, Lozano G. The intestinal epithelium compensates for p53-mediated cell death and guarantees organismal survival. Cell Death Differ 2008; 15: $1772-1781$.

30. Macedo E, Bouchard J, Mehta RL. Renal recovery following acute kidney injury. Curr Opin Crit Care 2008; 14: 660-665.

31. Molitoris BA, Dagher PC, Sandoval RM, Campos SB, Ashush H, Fridman E et al. siRNA targeted to p53 attenuates ischemic and cisplatin-induced acute kidney injury. J Am Soc Nephrol 2009; 20: 1754-1764.

32. Wei Q, Dong G, Yang T, Megyesi J, Price PM, Dong Z. Activation and involvement of p53 in cisplatin-induced nephrotoxicity. Am J Physiol Renal Physiol 2007; 293 F1282-F1291.

33. Terryn $\mathrm{S}$, Jouret F, Vandenabeele F, Smolders I, Moreels M, Devuyst $O$ et al. A primary culture of mouse proximal tubular cells, established on collagen-coated membranes. Am J Physiol Renal Physiol 2007; 293: F476-F485.

34. Muller T, Rumpel E, Hradetzky S, Bollig F, Wegner $\mathrm{H}$, Blumenthal $\mathrm{A}$ et al. Non-muscle myosin IIA is required for the development of the zebrafish glomerulus. Kidney int 2011; 80: 1055-1063. 
35. Siegerist F, Zhou W, Endlich K, Endlich N. 4D in vivo imaging of glomerular barrier function in a zebrafish podocyte injury model. Acta Physiol 2016 (e-pub ahead of print).

36. Grier JD, Yan W, Lozano G. Conditional allele of mdm2 which encodes a p53 inhibitor. Genesis 32: 145-147.

37. Traykova-Brauch M, Schonig K, Greiner O, Miloud T, Jauch A, Bode M et al. An efficient and versatile system for acute and chronic modulation of renal tubular function in transgenic mice. Nat Med 2008; 14: 979-984.

38. Jonkers J, Meuwissen R, van der Gulden $\mathrm{H}$, Peterse $\mathrm{H}$, van der Valk M, Berns A. Synergistic tumor suppressor activity of BRCA2 and p53 in a conditional mouse model for breast cancer. Nat Genet 2001; 29: 418-425.

39. Allam R, Pawar RD, Kulkarni OP, Hornung V, Hartmann G, Segerer $S$ et al. Viral 5'-triphosphate RNA and non-CpG DNA aggravate autoimmunity and lupus nephritis via distinct TLR-independent immune responses. Eur J Immunol 2008; 38 : 3487-3498. (c) (i) Cell Death and Disease is an open-access journal published by Nature Publishing Group. This work is licensed under a Creative Commons Attribution 4.0 International License. The images or other third party material in this article are included in the article's Creative Commons license, unless indicated otherwise in the credit line; if the material is not included under the Creative Commons license, users will need to obtain permission from the license holder to reproduce the material. To view a copy of this license, visit http://creativecommons.org/licenses/by/4.0/

(C) The Author(s) 2016

Supplementary Information accompanies this paper on Cell Death and Disease website (http://www.nature.com/cddis) 